IZA DP No. 5675

Broadband Internet:

An Information Superhighway to Sex Crime?

Manudeep Bhuller

Tarjei Havnes

Edwin Leuven

Magne Mogstad

April 2011 


\title{
Broadband Internet: An Information Superhighway to Sex Crime?
}

\author{
Manudeep Bhuller \\ Statistics Norway \\ Tarjei Havnes \\ University of Oslo \\ Edwin Leuven \\ CREST (ENSAE) and IZA \\ Magne Mogstad \\ Statistics Norway, ESOP and IZA \\ Discussion Paper No. 5675 \\ April 2011 \\ IZA \\ P.O. Box 7240 \\ 53072 Bonn \\ Germany \\ Phone: +49-228-3894-0 \\ Fax: +49-228-3894-180 \\ E-mail: iza@iza.org
}

Any opinions expressed here are those of the author(s) and not those of IZA. Research published in this series may include views on policy, but the institute itself takes no institutional policy positions.

The Institute for the Study of Labor (IZA) in Bonn is a local and virtual international research center and a place of communication between science, politics and business. IZA is an independent nonprofit organization supported by Deutsche Post Foundation. The center is associated with the University of Bonn and offers a stimulating research environment through its international network, workshops and conferences, data service, project support, research visits and doctoral program. IZA engages in (i) original and internationally competitive research in all fields of labor economics, (ii) development of policy concepts, and (iii) dissemination of research results and concepts to the interested public.

IZA Discussion Papers often represent preliminary work and are circulated to encourage discussion. Citation of such a paper should account for its provisional character. A revised version may be available directly from the author. 
IZA Discussion Paper No. 5675

April 2011

\section{ABSTRACT}

\section{Broadband Internet: An Information Superhighway to Sex Crime?*}

Does internet use trigger sex crime? We use unique Norwegian data on crime and internet adoption to shed light on this question. A public program with limited funding rolled out broadband access points in 2000-2008, and provides plausibly exogenous variation in internet use. Our instrumental variables and fixed effect estimates show that internet use is associated with a substantial increase in reported incidences of rape and other sex crimes. We present a theoretical framework that highlights three mechanisms for how internet use may affect reported sex crime, namely a reporting effect, a matching effect on potential offenders and victims, and a direct effect on crime propensity. Our results indicate that the direct effect is non-negligible and positive, plausibly as a result of increased consumption of pornography.

JEL Classification: J13, H40, I28, D31

Keywords: internet, broadband, instrumental variables, sex crimes, rape, pornography

Corresponding author:

Edwin Leuven

ENSAE

3, avenue Pierre Larousse

92245 MALAKOFF Cedex

France

E-mail: edwin.leuven@ensae.fr

\footnotetext{
* Thanks to Paul Devereux, Kjell Salvanes, Jesse Shapiro and a number of seminar and conference participants for helpful comments and suggestions. The project is part of the research activities at the ESOP center at the Department of Economics, University of Oslo. ESOP is supported by The Research Council of Norway.
} 


\section{Introduction}

The internet is a virtual treasure trove of information, and it has enabled new forms of social interactions through instant messaging, internet forums, and social networking. These fundamental changes have led to a growing interest among researchers and policymakers about the internet's impact on society..$^{1}$ In particular, the rapid growth of broadband internet has fueled a debate about how to shape and control this so-called superhighway to information and communication. Some have advocated that internet traffic should be controlled and monitored by government, just like conventional highway systems, while others argue for a more laissez-faire attitude. The debate has been particularly heated when it comes to how internet use affects the prevalence of sex crimes such as rape and child sex abuse, and whether policy interventions are called for. However, there is little if any causal evidence on the relationship between internet use and sex crime and - as discussed in detail below - much of what we know is either circumstantial or anecdotal.

In this paper, we use unique Norwegian data to examine the causal link between internet use and sex crime. We begin by estimating the net impact of internet use on rates of overall sex crime, rape and child sex abuse. As a source of exogenous variation in internet use, we exploit a public program introduced by the Norwegian government in the late 1990s. The program aimed at ensuring broadband internet access at a reasonable price throughout the country. Because of limited funding, access to broadband internet was progressively rolled out, so that the necessary infrastructure (access points) was established in different municipalities at different times. ${ }^{2}$ We use this spatial and temporal variation in the availability of broadband internet across municipalities in an instrumental variables (IV) setup: For each municipality and every year, we instrument the fraction of households with broadband internet subscription with the fraction of households that are covered by broadband infrastructure in the previous year. We show that our instrument is unrelated to municipality characteristics such as the poverty rate, immigrant population share, sex crime rate, and police density.

\footnotetext{
${ }_{1}^{1}$ Gentzkow and Shapiro (2010) find that media consumption on the internet is somewhat more ideologically segregated than is consumption of traditional media, though less segregated than face-to-face interactions. Freund and Weinhold (2004) and Choi $(2003)$ find that the internet has a positive effect on bilateral trade and foreign direct investment, while Yi and Choi (2005) and Choi and Yi (2009) suggest that the internet lowers the inflation rate and increases economic growth. Saint-Paul (2009) studies how internet search engines affect economic growth, while George (2008) and Ward (2007) examine how the internet affects the market for daily newspapers and local music stores, respectively.

${ }^{2}$ Throughout this paper, broadband internet is defined as internet connections with download speeds that exceeds $256 \mathrm{kbit} / \mathrm{s}$.
} 
Our IV estimates show that internet use is associated with a substantial increase in reported sex crime: Our baseline estimate suggests that in 2006 roughly one out of eleven rapes per 100,000 inhabitants would have been avoided if broadband internet had not been introduced. To learn about the characteristics of the complier group for our instrument, we take advantage of survey data on individuals' broadband subscription and accessibility. We find that the complier group is overrepresented by individuals who are more likely to be sex offenders, most notably young males. Having presented our main results, we take several steps to challenge the validity of the estimated net relationship between internet use and reported sex crime, finding little cause for worry.

We present a simple theoretical framework that highlights three possible mechanisms. First, internet use could increase reported crime without necessarily causing an increase in actual crime rates. Although it is not possible to report crime to the police on the internet, internet use may induce people to report crimes that they would otherwise not report. However, we find no evidence of changes in reported crime relative to charges or convictions, which would be expected if marginal reports are less strong. There are also no changes in the time elapsed between the crime and the report, suggesting again that reporting behavior was unaffected.

Next, we try to distinguish between the two other mechanisms. On the one hand, there may be a matching effect where the positive relationship between internet use and sex crime reflects that it is easier for sex offenders to meet their potential victims via chat rooms or other internet sites than through alternative activities. On the other hand, internet use can have a direct effect on the propensity for sex crime. In particular, internet reduces the pecuniary and non-pecuniary costs of (violent and/or extreme) pornography, which has often been linked to the propensity to commit sex crimes (e.g. Posner, 1992; Zillman, 1971).

Our results indicate that the direct effect is positive and substantial. First, we find no effect on other types of crime, where internet use might have an indirect effect through displacing alternative activities but should have little if any direct effect. Second, we exploit that the size of the direct effect is likely to vary systematically with access to non-internet pornography. In particular, we find a weaker effect of internet use on sex crime in municipalities close to the national border: While a legal ban on distribution of pornography was in place and enforced in Norway, pornography was legal and readily available in Sweden, the neighboring country. Although we admittedly cannot rule out matching or reporting effects, these results suggest that the positive net impact of internet use on sex crime is at least in part driven by the direct effect of internet use, plausibly as a result of increased consumption of 
pornography. This is consistent with many previous laboratory studies which support that pornography and sex crime are complements, and is in line with the well-known feminist slogan: "Pornography is the theory, and rape is the practice" (Morgan, 1978).

The paper unfolds as follows. Section 2 presents a theoretical framework to help structure our discussion of previous research related to the relationship between internet use and sex crime. Section 3 describes our data, before Section 4 describes the expansion of broadband internet, and Section 5 discusses our empirical strategy. Section 6reports our main findings as well as the results from a number of robustness checks. Section 7 investigates the alternative mechanisms through which internet use may affect reported sex crime, guided by our theoretical framework. Section 8 summarizes and concludes with a discussion of policy implications.

\section{Framework and related literature}

For a crime to happen, we need (at least) two individuals meeting each other. Let $\lambda$ be the rate (per year) at which people meet and $N$ the population size. Then $M=\lambda N$ is the number of matches of potential sex offenders and victims. If $p=\operatorname{Pr}($ crime $\mid$ match $)$ is the probability that a match leads to a crime then the number of committed crimes equals $C=p \cdot M$, which in per capita terms is

$$
c=p \cdot \lambda
$$

where $c=C / N$ is the crime rate. This setup can be justified using, for example, an underlying Poisson process where matches arrive at a given rate (Mortensen, 1988).

We are interested in how the internet user rate (per capita), $i$, affects the crime rate. In our data we observe reported crime rates $c^{*}$ which relate to committed crime rates as follows

$$
c^{*}=q \cdot c
$$

where $q=\operatorname{Pr}($ report $\mid$ crime $)$. We now discuss in turn how internet use may affect $p$, $\lambda$, and $q$.

\section{The effect of internet on crime propensity}

First, internet may affect the probability that a match leads to a sex crime, $p$. The prime suspect here is the consumption of internet pornography, as argued, for instance, by the US Congress in the passing of the Communications Decency Act in 1996 and the Children's Internet Protection Act in 2001. Indeed, pornography 
abounds on the internet, and since its early infancy distributors of pornography have exploited internet's 'Triple-A Engine' effect of Accessibility, Affordability, and Anonymity (Manning, 2005) . $^{3}$ The arrival of broadband internet further meant that distributors could offer explicit imaging of all kinds without excessive waiting times, in particular for movies 4

Let the propensity to commit a sex crime depend on a latent risk factor $\rho$, such that $p=p(\rho)$ where $\partial p / \partial \rho>0$. Several theories link the consumption of pornographic material to the risk factor $\rho$. One theory is that pornography increases the risk of sex crimes because it triggers sexual arousal and aggression, degrades women or children to objects, and affects social and individual norms, i.e. $\partial \rho / \partial p o r n>0$ (see e.g. Zillman, 1971; Dworkin, 1981; Mackinnon, 1995). An alternative theory emphasizes the potential cathartic effects of pornography consumption and argues that associated sexual relief (through masturbation) can decrease sexual aggression, i.e. $\partial \rho / \partial$ porn $<0$ (see e.g. Posner, 1992; Donnerstein et al., 1975). In either case, internet use and the propensity to commit a sex crime can be linked as follows

$$
\frac{\partial p}{\partial i}=\frac{\partial p}{\partial \rho} \frac{\partial \rho}{\partial p o r n} \frac{\partial p o r n}{\partial i}
$$

Since internet reduces the pecuniary and non-pecuniary cost of pornography, we expect that $\partial p o r n / \partial i>0$. This would in turn imply that the sign of $\partial p / \partial i$ is informative of the sign of $\partial \rho / \partial p o r n$, and vice versa.

However, there is little if any evidence on $\partial p / \partial i$, and most of what we know about $\partial \rho / \partial p o r n$ is either circumstantial or anecdotal. In the field, it has been argued that the pervasive use of pornography among sexual offenders indicates that $\partial \rho / \partial$ porn $>0$ (Gebert, 2003). Perhaps the most systematic evidence comes from psychology, where much effort has been devoted to laboratory experiments that study how subjects (typically male college students) respond to the exposure to pornography. Though some studies find no effect or a reduction in sexual aggression after exposure to pornography (see e.g. Zillman and Bryant, 1984), the majority of laboratory experiments do find that pornography increases sexual aggression, in

\footnotetext{
${ }^{3}$ See Kendall (2007) or Edelmann (2009) for detailed discussions of how (broadband) internet facilitates distribution and consumption of pornography. In 2006, the US online adult entertainment industry controlled about $12 \%$ of all internet sites (Ropelato, 2006), and pocketed 2.8 billion USD in revenue (Edelmann, 2009). Pornographic materials also abound on peer-to-peer networks, where for a period $73 \%$ of all movie searches were for pornographic films on the once dominant downloading engine Kazaa (Kendall, 2007).

${ }^{4}$ As an example, downloading a 5 -minute video clip of $35 \mathrm{MB}$ takes about 1.5 hours on a $56 \mathrm{kbps}$ dial-up line compared to just 5 minutes on a 1 Mbps DSL broadband connection, and just seconds on high-speed broadband connections. Edelmann (2009) reports that "[a]s of June 2008, broadband users outnumber narrowband users 18 to 1 at sites that comScore (2008) classifies as adult".
} 
particular as concerns violent pornography (Donnerstein et al., 1987; Allen et al. 1995). However, it is not clear whether this actually translates into higher crime rates in the field. The nature of both pornography consumption and expression of aggression is likely to be quite different in a controlled and supervised setting such as a laboratory (with no possibility of sexual relief), compared to more private settings..$^{5}$

\section{The effect of internet on matching}

The second channel through which internet can affect sex crimes is the rate at which potential offenders (men) meet victims (women), $\lambda$. It is widely documented that uncertainty and frictions play an important role in marriage markets (Mortensen, 1988). Recent literature has emphasized the potential role of the internet in increasing the efficiency of these markets. Hitsch et al. (2010) for example argue that search frictions in online dating markets are very small, suggesting that the matching rate depends on internet use. There are several ways in which the internet can increase the number of matches. First, internet can reduce information constraints. For example, dating sites allow searches based on personal characteristics such as age, education and profession, but also on less readily observed dimensions such as sexual preferences, hobbies and religion. Internet may also expand the choice set, making matches available that were previously unavailable, perhaps due to a lack of connection in traditional social networks. Finally, the anonymity that internet offers can also expand the pool of people looking for a match: Stevenson and Wolfers (2007) cite data from Forrester Research suggesting that over a third of online personals are placed by someone who is currently married.

At the same time, because more time spent online implies less time spent on other activities, internet can also cause a reduction in matching due to a incapacitation effect. There is also a potential substitution effect if social interaction through internet forums and social networks leads to less direct personal interaction.

The relationship between internet use and matching is therefore ambiguous. The relative weight of the various mechanisms will depend on the efficiency enhancing effect of the internet in the search process for mates, dates and friends. It will also depend on individual preferences and characteristics of the market participants. In light of the success of social networking, dating sites and chat rooms, there is surprisingly little evidence on these questions. Stevenson and Wolfers (2007) for example write that "While the Internet may yet transform marriage markets, it is too early to assess whether those matched on the Internet are better matched than

\footnotetext{
${ }^{5}$ See for example the related discussion in Dahl and Dellavigna (2009) in the context of movie violence, but also Levitt and List (2007a b) more broadly on lab experiments.
} 
they would have been without the Internet, whether marriage rates will subsequently rise, and what impact this will have on divorce."

The effect of internet on crime reporting

Finally, the internet may change the costs of reporting a crime and thus the reporting rate $q$. Because Norwegian police do not accept online crime reports, there is no direct link between internet use and the probability that a sex crime is reported. However, reporting costs may decrease if information and social interaction on the internet reduces the stigma of being the victim of a crime, for instance by increasing awareness or facilitating contact with victims or support groups. It is therefore possible that $\partial q / \partial i>0$, though we are not aware of any systematic studies of the relationship between crime reporting and internet use.

The effect of internet on reported sex crime

We can now write

$$
c^{*}(i, \rho)=q(i) \cdot c(i, \rho)=q(i) \cdot \lambda(i) \cdot p(\rho)
$$

To see how internet use may affect reported crimes, and how this relates to committed crime, we take the total derivative of (2) with respect to $i$.

$$
\begin{aligned}
\frac{d c^{*}}{d i} & =c \frac{\partial q}{\partial i}+q \frac{\partial c}{\partial i}+q \frac{\partial c}{\partial \rho} \frac{d \rho}{d i} \\
& =\underbrace{c \frac{\partial q}{\partial i}}_{\text {reporting }}+\underbrace{q p \frac{\partial \lambda}{\partial i}}_{\text {matching }}+\underbrace{q \lambda \frac{\partial p}{\partial \rho} \frac{d \rho}{d i}}_{\text {direct effect }}
\end{aligned}
$$

Equation (3) highlights that the net effect of internet use on reported crime consists of three distinct components. The first term shows that we need to distinguish between the effect on committed crime and the effect on reporting through $\partial q / \partial i$. The following two terms decompose the effect on actual crime into two channels: the direct effect of internet use on the latent risk factor for sex crime, $d \rho / d i$, and the effect of internet on the matching of potential victims and offenders, $\partial \lambda / \partial i$.

\section{Data}

Our analysis uses several data sources, which we can link through unique identifiers for each individual and every municipality. 


\section{Crime data}

Our crime data come from administrative police registers containing complete records of (i) reported crime for each municipality over the period 1993-2008, and (ii) individual criminal charges for every resident over the period 1993-2004. The dataset contains all serious crimes, but also misdemeanors like drunk driving, excessive speeding or shop lifting. A "reported crime" is defined as a crime reported to or recorded by the police. A person is registered as "charged" if, at the end of the investigation, they are considered to be the perpetrator of a reported crime by police and prosecutor (independent of potential indictments, prosecutions or convictions). Statistics Norway has constructed sub-categories of crime and we rely on these definitions to construct crime categories that correspond to those used by the US FBI (see the appendix, Table A1] ${ }^{6}$

A problem for any empirical study of crime is the difficulty in measuring criminal activity. Typically, measures are constructed from either self-reported survey data or from registered crimes. Self-reports of criminal activity should be interpreted cautiously since they are often impossible to validate and since there are incentives to misreport (MacDonald, 2002; Kirk, 2006). In particular, truthful self-reporting is less likely among subjects with an extensive criminal record compared to subjects with little or no criminal history (Hinderlang et al., 1981). A key advantage of our register data is that "reported crimes" are cleanly identified. In particular, our data exclude reports that are dismissed by police and prosecutor, because they are likely to be fraudulent or concern acts that are not criminal.7 Moreover, the register data have the advantage that offenders cannot choose not to be registered, unlike voluntary surveys where they may decline to participate.

A disadvantage of register data is that it excludes crimes which are not reported or not recorded by the police. Moreover, criminal charges require that the police identifies the offender. In line with previous studies, our main analysis focuses on reported crime rather than charges. This is in part because we do not have information on criminal charges after 2004, but also because the evidential burden is often difficult in these cases; which is mirrored in the fact that only in a quarter of cases are charges brought. Also, alleged rape offenders are unidentified in about a tenth of cases even after the investigation (Stene, 2001).

\footnotetext{
${ }^{6}$ Throughout this paper, our definition of sex crimes excludes crimes related to the distribution of pornography. Results are unchanged when these are included in the definition of sex crimes.

${ }^{7}$ In 1997, this concerned about $9 \%$ of reports on rape and other sexual activity, and about $7 \%$ on child sexual abuse (Stene, 2001).
} 


\section{Internet data}

Our internet data contain complete records of the fraction of households that subscribe to or are covered by broadband internet, in every municipality over the period 20002008. Throughout this paper, broadband is defined as internet connections with download speed that exceeds $256 \mathrm{kbit} / \mathrm{s}$.

The data on broadband coverage come from the Norwegian Ministry of Government Administration. The ministry monitors the coverage and use of broadband internet, and the suppliers of broadband access to end-users are therefore required to file annual reports about their coverage rates to the Norwegian Telecommunications Authority. The coverage rates are based on information on the area signal range of the local access points and detailed information on the place of residence of households. In computing the coverage rates on the municipality level, it is taken into account that multiple suppliers may provide broadband access to households living in the same area, so that we avoid double counting.

For the years 2000 and 2001, our data on broadband subscriptions come from the state-owned enterprise Telenor, which was the sole provider of broadband internet during this period. For the period 2002-2008, the data on broadband subscriptions are from the quarterly Internet Survey performed by Statistics Norway, surveying all suppliers of broadband access to end-users. The survey contains information on the aggregate number of households with broadband subscriptions in each municipality.

To explore the group of compliers to our instrument, we also exploit detailed information on media use for a representative sample of individuals at age 9-79, provided by Statistics Norway's Media User Survey. Each year, around 2700 individuals are asked detailed questions about their media use, with a response rate above $70 \%$. Importantly, the survey contains information on respondents age, sex, education, labor market status and some household characteristics, besides their internet use and connection speed. This survey data is available for the period 2000-2008.

\section{Socio-demographic data}

Our socio-demographic data come from administrative registers provided by Statistics Norway. Specifically, we use a rich longitudinal database which covers every resident from 1993 to 2008. It contains individual demographic information (sex, age, immigrant status, country of origin, marital status, number of children), socio-economic data (years of education, income, employment status), and geographic identifiers for municipality of residence. The information on educational attainment is based on annual reports from Norwegian educational establishments, whereas the income data and employment data are collected from tax records and other administrative 
registers. The household information is from the Central Population Register, which is updated annually by the local population registries and verified by the Norwegian Tax Authority. The coverage and reliability of Norwegian register data is considered to be exceptional, as illustrated by the fact that they received the highest rating in a data quality assessment conducted by Atkinson et al. (1995).

\section{Summary statistics}

In our main analysis, we use municipality-level data on crime rates, internet use and coverage rates, and other socio-demographic variables expressed in per capita terms. We focus on the years 2000-2008, when broadband internet coverage went from virtually zero to almost $100 \%$. Table 1 displays summary statistics for the key variables. Detailed descriptions of each of the variables are given in the appendix, Table A1

We use three different outcome variables, namely reported overall sex crime, reported rape and reported child sex abuse. 8 We define the outcome variables in terms of crime rates per 100,000 inhabitants. The first panel of Table 1 displays the mean of crime rates across municipalities, with standard deviations in parentheses. Rape and child sex abuse are the two main categories of sex crimes, making up nearly 25 and $45 \%$ of all sex crimes, respectively. The remaining categories are, for instance, procurement, prostitution and public exposé. It is also evident that the rate of sex crime is fairly stable, perhaps with a weakly increasing trend over the period. The time trend in overall crime is quite similar. Note that sex crime rates in Norway are similar to those in comparable countries. For instance, rape rates are almost identical to those in the UK, France and Germany, though somewhat lower than rates in the US (32 per 100,000) and Canada (78 per 100,000).9

The second panel of Table 2 shows means and standard deviations of internet coverage and user rates, defined as shares of households in a given municipality at the beginning of each year. We can see that there is no broadband use nor coverage in 2000. However, all households with a telephone connection would have dial-up access to internet, but limited to a bitrate of less than $56 \mathrm{kbit} / \mathrm{s}$. In 2008, mean broadband coverage is as high as $98 \%$, whereas the mean user rate reaches almost $54 \%$. We find the largest variation in coverage rates across municipalities around 2004, while the user rates vary the most during the last three years. Section 4 describes in detail the spatial and temporal variation in internet use and coverage.

\footnotetext{
${ }^{8}$ Notice that prostitution (though not procurement) is legal in Norway, and is hence not included in the crime statistics.

${ }^{9}$ Source: Seventh United Nations Survey of Crime Trends and Operations of Criminal Justice Systems, covering the period 1998-2000.
} 
The third panel of Table 1 displays a number of other socio-demographic variables, which are defined in Table A1 in the appendix. Local unemployment, poverty, urban settlement (centrality) and immigrant population are all defined in per capita terms. Most of these variables are shown to be fairly stable over the period. There is, however, an increase in the immigrant population share during the period. It is also evident that unemployment in Norway remained very low compared to most other European countries. We see that average years of education and police density were stable over the period. It should finally be noted that the estimations below will also control for a number of other control variables, including population shares by age-group and gender, as well as the population shares of immigrants by age, gender, country of origin, and refugee status (see the appendix, Table A1). For brevity, we omit summary statistics for these variables.

\section{Expansion of broadband internet}

During the 1990s, many OECD countries were planning the expansion of services related to information and communications technology. The new technology was seen as essential for retaining competitiveness and achieving high standards of living in a global economy. In particular, broadband internet was believed to reduce job-search costs, increase productivity in private enterprises and enable efficient provision of public services. In Norway, this manifested itself in the National Broadband Policy that was introduced by the Norwegian Parliament in May 1998 (St.meld.nr. 38 (19971998)). There were two main goals. The first was to ensure that every household and private enterprise throughout the country had access to broadband at a reasonable and uniform price. The second was to ensure that the public sector quickly adopted broadband internet.

The Norwegian government took several steps to reach these goals. First and foremost, it invested heavily in the necessary infrastructure. The investment in infrastructure was largely channeled through the state-owned telecom company Telenor, which was the sole supplier of broadband access to end-users in the early 2000s and continues to be the main supplier today. Moreover, virtually all broadband infrastructure was, and still is, owned and operated by Telenor.

Second, local governments were required to ensure access to broadband internet by 2005 to local public institutions, such as administrations, schools, and hospitals (St.meld.nr. 49 (2002-2003)). To assist municipalities in rural areas, the federal government provided financial support through a funding program known as Høykom, which was initiated in 1999. Local governments could receive funds from this program 
by submitting a project plan that had to be evaluated by a program board with expert evaluations. While the criteria determining selection are somewhat unclear, the board stated that it wanted to ensure broadband coverage throughout the country. Once approved, financial support was provided in the initial years of broadband access, thus making it possible for public institutions to cover relatively high initial costs (Hansteen, 2005; Statskonsult, 2007) 10

The transmission of broadband signals through fiber-optic cables required installation of local access points. Over the period 2000-2008, such access points were progressively rolled out, generating considerable spatial and temporal variation in broadband coverage. The staged implementation of broadband was in part due to limited public funding, but also because Norway is a large and sparsely populated country. There are often long driving distances between the populated areas, which are mostly far apart or partitioned by mountains or the fjord-gashed shoreline 11

Figure 2a displays the overall mean broadband coverage rate and the distribution of broadband coverage rates across municipalities at the start of each year between 2000 and 2008. There is considerable variation, both across municipalities and over time. In particular, the requirement of broadband internet access to public institution seems to have spilled over into increased coverage among households. This is mirrored by an increase in the average coverage rate from around $25 \%$ in 2003 to more than $85 \%$ by 2006 .

By December 2000, broadband transmission centrals were installed in the cities of Oslo, Stavanger, Trondheim and Troms $\varnothing$, as well as in a few neighboring municipalities of Oslo and Trondheim. However, less than one-third of the households were covered by a broadband service provider in each of these municipalities. Figure 1 shows geographic differences in the broadband coverage rates across municipalities between 2003 and 2006. The maps illustrate that for a large number of municipalities there was no broadband coverage at all before 2004, whereas most municipalities had achieved fairly high coverage rates after 2006. Moreover, there is considerable variation in coverage rates within the municipalities in these years. We find the

\footnotetext{
${ }^{10}$ During the period 1999-2005, the Høykom program received more than 1000 such applications and co-funded nearly 400 projects, allocating a total of 50 million Euros (NOK 400 million), provided initially by the Ministry of Trade and Industry. From 2002, the Ministry of Education and Research co-financed another scheme Høykom skole dedicated to the education segment within the scope of the earlier program, as it opened for financial support for broadband infrastructure in public schools. There are virtually no private schools in Norway.

${ }^{11}$ The Norwegian territory covers about 149,400 square miles, equivalent to the area of the US states of Delaware, District of Columbia, Pennsylvania, Maryland, South Carolina, Virginia and West Virginia combined. The country is dominated by mountainous or high terrain, as well as a rugged coastline stretching about 2,650 kilometers, broken by numerous fjords and thousands of island (making the coastline approximately 10 times longer if the length of the fjords were included).
} 
largest dispersion in coverage rates across municipalities between 2004 and 2005. While almost complete broadband coverage was reached by 2008, more than $50 \%$ of households in nearly all municipalities were covered by a broadband provider two years earlier.

Figure 2b displays the distribution and averages of broadband user rates across municipalities between 2000 and 2008. Broadband use increases over time, with most of the increase taking place after 2003, and reaching an average user rate around $55 \%$ by 2008 . We find that there was a substantial increase in broadband use after the initial expansion of broadband coverage. Moreover, there was a considerable increase in broadband use also after 2006, even though there was less of an increase in broadband coverage in these later years.

\section{Empirical strategy}

We employ two approaches to estimate the net effect of internet use on sex crime. Our first approach is a fixed effect specification, controlling for permanent differences in crime rates between municipalities, as well as for common time-specific changes in crime rates. Our second approach implements an IV-strategy with two-stage least squares, using the spatial and temporal variation in the availability of broadband internet across municipalities to instrument for internet use.

Our empirical approaches are summarized by the following two equations.

$$
\begin{aligned}
c_{k t}^{*} & =\delta i_{k t}+x_{k t}^{\prime} \beta+\alpha_{k}+\tau_{t}+\epsilon_{k t} \\
i_{k t} & =\phi z_{k t-1}+x_{k t}^{\prime} \lambda+\gamma_{k}+\theta_{t}+\eta_{k t}
\end{aligned}
$$

where $c^{*}$ is the reported sex crime rate per 100,000 inhabitants, $i$ is the fraction of households with broadband internet subscriptions (at the beginning of the year), $z$ is the fraction of households with access to broadband internet (at the beginning of the year), and $x$ is a set of time-varying covariates (measured at the municipality level in per capita terms). In all cases, the subscript $k$ denotes municipality and the subscript $t$ denotes year. Both equations include a full set of municipality indicators and year indicators. In our main analysis, the sample consists of all municipalities over the period 2000-2008. The standard errors are always clustered at the municipality level and robust to heteroskedasticity.

The fixed effect approach is given by equation (4), and can be interpreted as giving a difference-in-differences estimate of the effect of internet use on sex crime: Unobservable determinants of crime that are fixed at the municipality level will be controlled for through the municipality indicators $\alpha_{k}$, just like common time shocks 
are absorbed by the year indicators $\tau_{t}$. In the IV-approach, equation (5) is the first stage and equation (4) is the second stage.

In both approaches, we report results with and without a large set of time-varying socio-demographic controls $x$, to check that the estimated effect is not driven by time-varying observable factors. For example, younger individuals are more likely to use internet and are also more often involved in a sex crime. If some municipalities experience growth in the number of young inhabitants, then this could increase both internet use and sex crimes, which would bias the fixed effect estimates. We therefore include detailed controls for demographic characteristics. The control variables are listed in Table A1, and include population shares by age-group, gender and immigrant status, as well as centrality of residence, education level, income level, poverty rate, and unemployment rate 12 Another concern is that public funding to broadband infrastructure across municipalities might be correlated with the amount of resources allocated to the police, which could bias our estimates. This concern is addressed by including the number of police officers per capita as a control variable. Finally, there may be some underlying trend in crime that is correlated with the expansion of broadband internet. To address this concern, we also add the total crime rate (excluding sex crimes) at the start of the year as a control variable ${ }^{13}$

Despite the fact that Norway has a homogeneous population with a unified legal system and law enforcement practices across the country, the identifying assumption in the fixed effect approach of a common underlying time trend in sex crime between municipalities might be too strong. On the one hand, individuals who are more likely to commit a sex crime may also be more likely to use the internet, because they want to consume internet pornography. This will generate upward bias in the fixed effect estimates. On the other hand, potential sex offenders may be more likely to use internet, to seek sexual relief through pornography, in areas where there are fewer potential victims or more strict policing. This may lead to a downward bias in the fixed effect estimates. These examples illustrate that the fixed effect estimates may suffer from omitted variables bias, but also that the direction of the bias is unclear.

Although our vector of controls $x$ should take into account some of the confounding factors, it is widely documented that observables explain only a small portion of the observed variation in crime (Glaeser et al., 1996). Randomizing internet use is not feasible in our application: We cannot in practice force internet use onto people.

\footnotetext{
${ }^{12} \mathrm{We}$ allow for a flexible functional form by including a large set of dummies for different values of the controls listed in Table A1.

${ }^{13}$ Note that police resources and other reported crime are potentially endogenous to sex crimes. It is therefore useful to include them separately, and comforting to note that estimates barely move when they are included.
} 
One can, however, think of a social experiment which randomizes internet access at the municipality level. The randomization breaks the correlation between access and unobserved determinants of crime. On the one hand, comparing crime rates between municipalities with and without internet access would give the effect of internet access on crime. On the other hand, comparing internet use between these municipalities, would give the effect of internet access on internet use. Taking the ratio between the two would give an IV estimate of internet use on crime, using random access to internet as an instrumental variable.

The intention of our IV-approach is to mimic this hypothethical experiment. Our source of exogenous variation comes from the staged installation of broadband infrastructure, generating spatial and temporal variation in broadband coverage rates. Section 4 describes this plausibly exogenous supply shock. For each municipality and every year, we instrument $i_{k t}$, the fraction of households with broadband internet subscriptions, using $z_{k, t-1}$, the fraction of households that are covered by broadband infrastructure in the previous year. This IV-approach may then identify the average effect of internet use on sex crime for the sub-population that is induced to use internet because of the increase in coverage in the previous year. Following Imbens and Angrist (1994), we refer to this sub-population as compliers, and to the IV estimate as the local average treatment effect (LATE).

Because we control for municipality fixed effects and time-varying observables, it is not necessary that the timing of the internet expansion is unrelated to municipality characteristics. It is useful, however, to understand the determinants of the timing of the expansion across municipalities. To examine this issue further, we estimate the following equation

$$
\Delta z_{k t}=\gamma_{k}+\left[\theta_{t} \times m_{k, 2000}\right]^{\prime} \psi_{t}+\chi_{k t}
$$

where $\Delta z_{k t}=z_{k t}-z_{k t-1}$ and $m_{k, 2000}$ includes municipality-level information from year 2000 on average years of education, unemployment rate, poverty rate, number of policemen per capita, immigrant population share, share of population residing in a densely populated locality (a centrality indicator), baseline sex crime rate, and industry composition.

Figure 3 plots the estimated coefficients from the vector $\psi_{t}$ for every $t$ (and the associated $95 \%$ confidence intervals). Consistent with the discussion in Section 4, our results indicate that broadband expansion is positively related to centrality, educational attainment and population size until the beginning of 2003. From 2004 onwards, there appears to be no systematic relationship between the timing of the broadband expansion and these variables. But more importantly, the timing of 
the expansion does not seem to be correlated with background variables such as immigrant population share, local unemployment rate, poverty rate, police density, or (baseline) sex crime. Although it is reassuring that the broadband internet expansion is uncorrelated with such risk factors of sex crime, we cannot rule out that our instrument is correlated with time-varying unobservable determinants of sex crime which would bias our IV estimates. To further increase our confidence in the IV-approach, we therefore run several specification checks.

\section{$6 \quad$ Net effect of internet use on sex crime}

Below, we begin by reporting estimates of the fixed effect model, before turning attention to the IV estimates. Next, we take advantage of survey data on individuals' broadband subscription and accessibility, to learn about the characteristics of the complier group for our instrument. This allows us to better interpret the IV estimates, and compare them to the fixed effect results. We then consider the economic significance of our estimates by comparing the actual crime rate to the estimated counterfactual crime rate in the absence of the expansion of broadband internet. Next, we demonstrate that our results are supported by a number of specification checks. We conclude this section with a comparison between our analysis and a related study by Kendall (2007).

\section{Fixed effect estimates}

Table 2 displays the fixed effect estimates from equation (4) per percentage point increase in the internet user rate. The first column shows the results from a specification with only municipality and year fixed effects. The first row suggests that when the internet user rate increases by 1 percentage point, the overall crime rate increases on average by 0.47 crimes per 100,000 inhabitants. The next two rows report the estimates for rape and child sex abuse. We see that a 1 percentage point increase in internet use is associated with an increase in rapes of 0.14 and an increase in child sex abuse of 0.16 , per 100,000 inhabitants. The effects on the overall sex crime rate and rapes are precisely estimated, being statistically significant at the $5 \%$-level.

We then add control variables to see whether the fixed effect estimates are biased because of omitted time-varying observable factors. The second column adds demographic controls to the fixed effect specification. The estimated effects are very similar and probably reflects the homogeneous Norwegian population. A second potential threat to the estimates are changes in the costs of committing crimes that are correlated with internet use. It is therefore reassuring to see that our estimates 
barely move when adding a control for the number of policemen per capita in the municipality. A third worry is that there is some underlying trend in crime that is correlated with internet use. To address this concern, the last column of Table 2 also adds the total crime rate (excluding sex crimes) as a control. Again the estimates barely move.

\section{IV estimates}

The fixed effect specification provides consistent estimates of the net relationship between internet use and sex crime, insofar as the systematic unobserved determinants of internet use are additive, time-invariant municipality characteristics. Our IV strategy relaxes this assumption by exploiting a plausibly exogenous supply shock to instrument for internet use. Table 3 reports results from the IV-approach given by equations (4) and (5). The first column shows the estimates from the specification

with only municipality fixed effects and time dummies. The first stage instruments the user rate in a municipality in year $t$ with the coverage rate at the start of the year. The first stage coefficient on the coverage rate is about 0.13 which is also the size of the complier group since the instrument ranges from 0 (nobody covered) to 1 (everybody covered). It implies that a 10 percentage point increase in internet coverage induces (an additional) $1.3 \%$ of the population to use internet within the next year. The first stage is strong, with an $F$-statistic around 323, which means weak instrument bias is not a concern.

Turning to the second stage results in the first column we see that when the internet user rate increases by 1 percentage point, the overall crime rate increases on average by 1.15 crimes per 100,000 inhabitants. The next two rows report the IV-estimates for rape and child sex abuse. We find that a 1 percentage point increase in internet use causes an increase in rapes of 0.38 and an increase in child sex abuse of 0.62 , per 100,000 inhabitants.

We include control variables to see to what extent the IV-estimates of internet use on sex crime are sensitive to the inclusion of time-varying observable factors. We first add demographic controls in the second column which does not affect the first stage estimate, nor the estimated effects on overall sex crime rate and rapes. Only the effect of internet use on child sex abuse drops by about $30 \%$ but remains substantial, although it is no longer significant at the $10 \%$-level. The final two columns add controls for police density and other types of crime, which barely moves our estimates. 
There are at least two reasons why the fixed effect estimates and the IV estimates can differ. First, the fixed effect estimates are more likely to suffer from omitted variable bias. Second, fixed effect estimates that are not biased will be closer to average effects for the population at large, whereas the IV estimates should be interpreted as the LATE for the subgroup of compliers who were induced to use internet because of the increase in coverage in the previous year 14

To learn about the characteristics of the complier group, we use our survey data on individual's internet use in the period 2000-2008 to estimate the first stage of the IV for different gender-age groups. These estimates are shown in the second column of Table 4. We see that the expansion of broadband internet has a stronger effect on the young than the old, and that effects are also stronger among males than among females. The proportion of the compliers in a given gender-age group are then calculated as the ratio of the first stage for that subgroup to the overall first stage, multiplied by the proportion of the population in the gender-age group (Angrist and Pischke, 2009). Column 1 displays the proportion of the population in each gender-age group, wheras column 3 shows the distribution of the compliers by gender and age. Column 4 displays the relative likelihood of an individual belonging to a particular gender-age group, in the complier group compared to the population at large. While $29 \%$ of the population are males aged 16-44, more than $43 \%$ of the compliers are males in this age-group. When including females, around $82 \%$ of the compliers are aged 16-44, compared to just $57 \%$ in the population at large. We also see that males are overrepresented among the compliers in every age group compared to the population at large.

Finally, columns 5-7 of Table 4 report the probability of being charged with a sex crime for the different gender-age groups. While sex crimes are almost uniquely committed by males, young males are much more likely to be offenders than older males. Males aged 16-24 are for instance more than twice as likely to be charged with a sex crime than men aged 45-66. We calculate re-weighted sex crime rates to get a rough idea of the extent to which the IV estimates are driven by the different gender-age composition of the complier group. We simply take the weighted average of the sex crime probabilities by gender-age group using the complier shares as weights. We find that the re-weighted sex crime rate is $60 \%$ higher than the actual crime rate in the population at large. It should therefore not be surprising to find

\footnotetext{
${ }^{14} \mathrm{~A}$ third possible explanation is that measurement error in the user rate creates attenuation bias in the fixed effect estimates. In comparison, the IV estimates will not be prone to such attenuation bias, as it uses only the variation in internet use that is induced by the change in coverage rates.
} 
that the LATE estimated in our IV-approach is larger than the estimates from the fixed effect approach.

\section{Economic significance}

To put the size of our IV estimates into perspective, we calculate the counterfactual sex crime rate that would have occured in the absence of the expansion of broadband internet. The counterfactual sex crime rate is given by the actual crime minus the predicted effect of internet use on sex crime for the compliers. In each year, the predicted effect of internet use on sex crime is calculated as the percentage point increase in the coverage rate in the previous year multiplied by the first stage times the LATE (Angrist and Pischke, 2009).

Figure 4 shows the actual time trends for our various outcomes, and the predicted counterfactual time trends based on our baseline IV estimates, reported in column 4 of Table 3. Panel (a) reports these for all sex crimes, whereas panels (b) and (c) focus on rape and child sex abuse. Until 2003, the actual and counterfactual trends coincide because of very low increases in coverage. From 2003, the coverage rates quickly increased. We then see a substantial difference between the actual and counterfactual sex crime rates. The difference peaks in 2006, when we estimate that roughly three out of 50 sex crimes per 100,000 inhabitants would have been avoided if broadband internet had not been introduced. Our analysis also suggests that internet use in 2006 explains about one out of eleven rapes and one out of 22 child sex abuses, per 100,000 inhabitants.

\section{Specification checks}

We just saw that our estimates are robust to the inclusion of a wide range of controls. We now report results from additional specification checks to further increase our confidence in the IV-results. An important requirement for our IV-approach to be valid is that the expansion of broadband internet is unrelated to different underlying time trends in sex crime across municipalities. As a first check for this possibility we estimate municipality-specific trends using data covering the period prior to the internet expansion, namely 1993-2000. For each municipality we obtain a slope estimate $\hat{\nu}_{k}$. We then extrapolate pre-expansion time trends in our specification (both the first and the second stage) as follows

$$
c_{k t}^{*}=\delta i_{k t}+x_{k t}^{\prime} \beta+\alpha_{k}+\lambda_{1} \hat{\nu}_{k} t+\lambda_{2} \hat{\nu}_{k} t^{2}+\tau_{t}+\epsilon_{k t}
$$


which will take into account any variation in our instrument that coincides with pre-existing trends in the outcome. Columns (5) and (6) in Table 3 report the estimates based on these specifications, which are nearly identical to our baseline estimates.

A second and related test follows Duflo (2001) in interacting baseline (year 2000) covariates either with a linear time trend

$$
c_{k t}^{*}=\delta i_{k t}+x_{k t}^{\prime} \beta+\alpha_{k}+t \sum_{j} \lambda_{j} x_{(k, 2000), j}+\tau_{t}+\epsilon_{k t}
$$

or with time dummies

$$
c_{k t}^{*}=\delta i_{k t}+x_{k t}^{\prime} \beta+\alpha_{k}+\tau_{t} \sum_{j} \lambda_{j} x_{(k, 2000), j}+\epsilon_{k t}
$$

In doing so, we allow the expansion of broadband internet to be related to different underlying time trends in sex crime across municipalities, depending on their prereform characteristics. The final two columns in Table 3 report the estimates based on equations (8) and (9). Again we find that these are close to our baseline estimates; if anything, the robustness check of interacting the covariates with time dummies indicate that the baseline IV specification understates the positive effect of internet use on sex crime.

We have also performed two placebo tests. The first replaces current crime rates and control variables with the same variables from eight years before, while maintaining current internet use and coverage. In doing so, this pre-reform placebo test places the internet expansion in the period before the actual roll-out. Since there was no broadband internet expansion during the period 1993-2000, significant estimates would suggest that the instrument is correlated with underlying municipality-specific trends in sex crime. Table 5 reports the results using these pre-reform outcomes. First note that, as expected, the first stage is very similar, changing only slightly because of the time shift of the regressors. More importantly, in none of the three second stages do we find an impact of internet use on sex crime. This reinforces our confidence that we are indeed estimating the effect of internet use in Table 3, and are not picking up differential secular trends in sex crime.

The second placebo test examines whether next year's internet use affects current sex crimes: If it did, this would suggest that there was some omitted variable causing both sex crimes and internet use. We regress the sex crime rate in year $t$ on internet use in the following year $t+1$, and instrument internet use in year $t+1$ with the coverage rate in year $t$. We control for the coverage rate in year $t-1$, our original instrument, to ensure that we are indeed estimating the effect of next year's internet 
use through future variation in our instrument ${ }^{15}$ The final column of Table 5 shows the estimates from this placebo test. It is reassuring to find that next year's internet use does not affect the rates of overall sex crimes, rape or child sex abuse.

In addition, in Table A2 in the appendix, we make sure that our estimates are not driven by observations with extreme values for sex crimes or zeros. Furthermore, we examine whether our results are driven by secular changes between urban and rural areas that may have coincided with the internet expansion. This may also be a concern since we found in Figure 3 that broadband internet arrived earlier in more central and larger municipalities. When we drop the five large cities from our analysis (Oslo, Bergen, Trondheim, Stavanger and Kristiansand), the estimates barely move.

Finally, we check whether our estimates are affected by spillovers or sorting. In our analysis, crime is measured at the municipality level. This will give consistent estimates as long as crimes are committed in the same municipality where internet is used. In principle, crimes could be committed in, for example, neighboring municipalities. This would probably lead to a downward bias. To check for such spillovers we broaden our outcome measure to include sex crimes that are committed in adjacent municipalities, while controlling for the broadband internet expansion there. Column (5) in Table A2 in the appendix reports the resulting estimates which are very close to our baseline.

Sorting across municipalities could also affect the interpretation of our results. In theory, individuals at risk for committing sex crimes may move to municipalities that expand broadband internet. However, the information requirements to generate such behavior are probably high, since people would need information on the exact timing of the infrastructure expansion. Moreover, the cost of moving is probably high relative to the benefits, since broadband internet becomes available across the country after a few years, making the benefits short-lived. We nevertheless check whether our instrument correlates with movements into and out of the municipality, by estimating equation 5 with population growth (in percent) as the dependent variable. We estimated this effect for the population at large and separately for younger men and women who are overrepresented in the complier group. The results are shown in Table A3, and confirm that confounding effects due to sorting are unlikely to be a concern.

\footnotetext{
${ }^{15}$ Since the coverage rate is cumulative, not controlling for coverage rates in the previous year would raise the concern that we are incorporating variation that precedes the sex crime rate. It turns out, however, that the estimates without the control for coverage rates in the previous year are very similar and never statistically significant ( $t$-statistic never exceeds 1 ).
} 


\section{Discussion}

Closely related to our paper is the study by Kendall (2007). Using US state-level panel data from 1998-2003, he regresses the fraction of households with an internet subscription on rape incidences. In contrast to our findings, Kendall reports a negative association between internet use and rape. Our study differs from Kendall's in a number of respects. First of all, several features of the Norwegian setting make it possible to arrive at estimates that are potentially less biased. Unlike the US, Norway has a homogeneous population spread out over more than 400 geographically distinct municipalities. Importantly, the municipalities are subject to a common institutional and judicial infrastructure, and they have very similar spending on local public services ${ }^{16}$ The legal system and law, including criminal law, are determined nationally, and the 27 police districts and 67 district courts do not in general share borders with a municipality. Budgetary, administrative and strategic responsibility for the police and the courts rest nationally with the Police Directorate, the National Courts Administration, and the Ministry of Justice and Police. Second, while Kendall's fixed effect identification assumes that the systematic determinants of internet use are additive, time-invariant state characteristics, we relax this assumption by exploiting plausibly exogenous supply shocks to instrument for internet use.

It should finally be noted that the arrival of the internet most likely implied a much stronger shock to the availability of pornography in Norway compared to the US. While pornography was de facto legalized and readily available in most of the US, a legal ban on pornography was in place in Norway. Access to pornography was therefore severely limited in Norway before the arrival of broadband internet, especially with respect to movies and other moving images. Hence, even in the absence of omitted variable bias, there could be differences between our estimates and those of Kendall.

\section{Mechanisms}

We have established that internet use increases reported sex crimes. This section explores the three mechanisms highlighted in Section 2, related to reporting, matching of potential offenders and victims, and the latent risk factor for sex crime.

\footnotetext{
${ }^{16}$ There are strict national provisions for minimum standards of different local public services, and considerable ear-marked grants-in-aid from the central government. The national government also determines the tax rate (except for an optional residential tax capped at $1 \%$ ) and the tax base of the income tax. Also, the national government uses equalization transfers to redistribute income from rich to poor municipalities, such that local differences in revenues are largely offset (Løken, 2009).
} 


\section{Reporting behavior}

The first possible mechanism is that internet use increases crime reporting without having caused an increase in the underlying crime rates. To investigate this possibility we start by considering charges brought by police and prosecutor, relative to reported crimes. Though it is not possible to report crime to the police on the internet in Norway, internet use may induce people to report crimes that they would otherwise not have reported, for example by creating contact points with victims groups. We expect that, everything else equal, crimes are more likely to be reported the more likely it is that charges will be made. If internet use caused an increase in reporting, then the marginal reports would probably be weaker on average. This would lead to a drop in the ratio of charges to reports as internet became more common. Figure 5 shows that on the contrary charges-to-reports ratios are quite stable between 1993 and 2004 (the last year for which we have data on charges) for sex crimes, rapes and child sexual abuse alike, giving no indication of an increase in the number of reports. To strengthen this result we also estimated the effect of internet use on the charges-to-reports ratio using our IV-approach, including all controls. Table 7 reports the estimates for the different types of sex crimes, and in line with Figure 5 . we find no significant effects. We have also estimated the effect of internet use on conviction rates relative to reported crime rates for the years 2000-2004, and found no evidence of an effect.

We next consider the time from the reported crime was (allegedly) committed to the time of the report itself. Changes in the timing of reports relative to the crime would suggest changes in reporting behavior that could in principle also have an effect on the likelihood of charges. For instance, if the crime is more recent at the time of the report, then witnesses and other evidence may be more forthcoming. Such changes in reporting may not be reflected in Figure 5. Information on time to report is also available for a longer time period (2001-2008) than information on charges (2001-2004). We again use our IV-approach to estimate the effect of internet use on the time between the crime and the report (measured in days). Again these estimates, reported in Table 7, reveal no evidence of changes in reporting behavior.

\section{Direct and indirect effect of internet use}

Although we do not find evidence of an effect of internet use on reporting, we still want to distinguish whether our estimated effects are driven by an indirect effect increasing the likelihood of matches $(\partial \lambda / \partial i)$, or by a direct effect on the risk factor for sex crime itself $(\partial \rho / \partial i)$. A first check considers the effect of internet on crimes other than sex crimes. This would consist of only the indirect matching effect under 
the assumption that for these crimes the latent crime factor is not affected by internet (i.e. $\partial \rho / \partial i=0)$. As argued above, the indirect effect could arise if internet use displaces alternative activities (both during and after use) that are more or less associated sex crime ${ }^{17}$ For instance, if activities on the internet imply that people stay more at home, then this is likely to affect all crimes, not only sex crimes. We perform this check for all crimes (excluding sex crimes) as well as for the types of crime that are the most highly correlated with sex crime over time. Table A1 reports the results, suggesting that internet has no effect on non-sex crime.

A second test exploits that the effect of internet use is likely to vary systematically with access to non-internet pornography. With easier prior access to pornography, the effect of internet on the latent risk factor, $\partial \rho / \partial i$, should be smaller. This suggests that the total effect will be mostly driven by the indirect effect in areas where the supply shock is small, while the direct effect will be more important in areas where the supply shock is large. Municipalities on the border with Sweden could more easily take advantage of the liberal laws governing pornography in this country. Meanwhile, there is no reason to believe that there should be systematic differences in the effect through matching between border and non-border areas. The difference in the effect of internet use between these two areas should therefore reflect an effect on the propensity for sex crime, not matching. Results from separate estimations using our fixed effect approach and our IV-approach are reported in Table 8. The effects of internet use on sex crime are weaker in border areas than in non-border areas. While effects compared to our baseline estimates are somewhat larger in non-border areas, they are cut almost in half in border areas. This suggests that the direct effect on crime propensity, $d \rho / d i$, is (a) an important factor behind our results, and (b) that the direct effect is positive, in line with the results from the experimental psychology literature discussed in Section 2 .

\section{Conclusion}

Does internet use trigger sex crime? We use Norwegian registry data on crime and internet adoption to shed light on this question. A public program with limited funding rolled out broadband access points in 2000-2008, and provides plausibly exogenous variation in internet use. Our IV and fixed effect estimates suggest that internet use is associated with a significant increase in reported incidences of rape and other sex crimes. We present a theoretical framework that highlights three

\footnotetext{
${ }^{17}$ Dahl and Lochner (2009) find that violent crime decreases on days with larger theater audiences for violent movies. This finding is partly due to voluntary incapacitation during movie attendance, but also because of a substitution away from dangerous activities after movie attendance.
} 
mechanisms for how internet use may affect reported sex crime, namely a reporting effect, a matching effect on potential offenders and victims, and a direct effect on crime propensity. Our results suggest that the direct effect is positive and empirically important, plausibly as a result of increased consumption of pornography.

Our study speaks to an ongoing policy debate in many countries about whether and how internet traffic, with the abundant online supply of extreme pornography, should be controlled and monitored by government to prevent sex crime, such as rape and child sex abuse. In 1996, the US congress passed the Communications Decency Act in an effort to regulate pornographic material on the Internet, while the Children's Internet Protection Act was passed in 2001. In 2005, the US Attorney General formed the Obscenity Prosecution Task Force to pursue in particular producers of extreme pornography. The task force has since successfully litigated cases against publishers of extreme pornography, for instance the 2008 case against Paul Little who was sentenced to 46 months in prison and a $\$ 1.4$ million fine for distribution of obscene material. The opposition to pornography is hardly restricted to the US. In China, internet pornography was banned in 2002, and the production of pornographic movies was banned in 2008. While possession of pornography may give prison terms up to 3 years long, large distributors of pornography may face execution.

While one could argue that our findings support censorship or regulation of internet pornography because of its harms to third parties, caution is in order. Though our results suggest that internet use increases the propensity for sex crime, matching effects may also be important. From a policy perspective, it is critical to pin down the exact channel: If the matching effects are important, then an appropriate policy response may rather be to improve transparency and inform about the dangers on internet forums and social networking sites.

\section{References}

Allen, M., D’Alessio, D., and Brezgel, K. (1995). A meta-analysis summarizing the effects of pornography ii aggression after exposure. Human Communication Research, 22:258-283.

Angrist, J. and Pischke, S. (2009). Mostly Harmless Econometrics. Princeton University Press.

Atkinson, A. B., Rainwater, L., and Smeeding, T. M. (1995). Income distribution in OECD countries : evidence from the Luxembourg Income Study. OECD Publications and Information Center, Paris. 
Beatty, T. K., Larsen, E. R., and Sommervoll, D. E. (2009). Driven to drink: Sin taxes near a border. Journal of Health Economics, 28(6):1175-1184.

Choi, C. (2003). Does the internet stimulate inward foreign direct investment? Journal of Policy Modeling, 25(4):319-326.

Choi, C. and Yi, M. H. (2009). The effect of the internet on economic growth: Evidence from cross-country panel data. Economics Letters, 105(1):39-41.

Dahl, G. and Dellavigna, S. (2009). Does movie violence increase violent crime? Quarterly Journal of Economics, pages 677-734.

Donnerstein, Linz, and Penrod (1987). The Question of Pornography. Research Findings and Policy Implications. New York: The Free Press.

Donnerstein, E., Donnerstein, M., and Evans, R. (1975). Erotic stimuli and aggression: Facilitation or inhibition. Journal of Personality and Social Psychology, 32:237-244.

Duflo, E. (2001). Schooling and labor market consequences of school construction in indonesia: Evidence from an unusual policy experiment. American Economic Review, 91(4):795-813.

Dworkin, A. (1981). "Pornography": Men Possessing Women. The Women's press, London.

Edelmann, B. (2009). Red light states: Who buys online adult entertainment? Journal of Economic Perspectives, 23(1):209-220.

Freund, C. L. and Weinhold, D. (2004). The effect of the internet on international trade. Journal of International Economics, 62(1):171-189.

Gebert, V. (2003). Sex-Related Homicide and Death Investigation: Practical and Clinical Perspectives. New York: Practical Homicide Investigation Inc.

Gentzkow, M. A. and Shapiro, J. M. (2010). Ideological segregation online and offline. Research Paper 10-19, Chicago Booth.

George, L. M. (2008). The internet and the market for daily newspapers. The B.E. Journal of Economic Analysis \& Policy, 8(1).

Glaeser, E. L., Sacerdote, B., and Scheinkman, J. A. (1996). Crime and social interactions. The Quarterly Journal of Economics, 111(2):507-48. 
Hansteen, K. (2005). Norwegian and swedish broadband initiatives (1999 - 2005). HØYKOM-rapport 505, HØYKOM.

Hinderlang, M., Hirschi, T., and Weis, J. (1981). Measuring Delinquency. Sage, Beverly Hills, CA.

Hitsch, G., Hortacsu, A., and Ariely, D. (2010). Matching and sorting in online dating. The American Economic Review, 100(1):130-163.

Imbens, G. W. and Angrist, J. D. (1994). Identification and estimation of local average treatment effects. Econometrica, 62(2):467-75.

Kendall, T. D. (2007). Pornography, rape, and the internet. Mimeo, Clemson University.

Kirk, D. (2006). Examining the divergence across self-report and official data sources on inferences about the adolescent life-course on crime. Journal of Quantitive Criminology, 22:107-29.

Levitt, S. D. and List, J. A. (2007a). Viewpoint: On the generalizability of lab behaviour to the field. Canadian Journal of Economics, 40(2):347-370.

Levitt, S. D. and List, J. A. (2007b). What do laboratory experiments measuring social preferences reveal about the real world? Journal of Economic Perspectives, 21(2):153-174.

MacDonald, Z. (2002). Official crime statistics: Their use and interpretation. The Economic Journal, 112:F85-F106.

Mackinnon, C. (1995). Only Words. Harper Collins, London.

Manning, J. C. (2005). The impact of internet pornography on marriage and the family: A review of the research. Testimony before the US Senate, Subcommittee on the constitution, civil rights and property rights.

Morgan, R. (1978). Going too far. New York: Vintage books.

Mortensen, D. (1988). Matching: finding a partner for life or otherwise. American Journal of Sociology, 94(1):215-240.

Posner, R. T. (1992). Sex and Reason. Harvard University Press.

Ropelato, J. (2006). Internet pornography statistics. TopTenReviews.com. http://internetfilter-review.toptenreviews.com/internet-pornographystatistics.html - Reading date: 2010/05/20. 
Saint-Paul, G. (2009). Economic growth and the design of search engines. Birkbeck Working Papers in Economics and Finance 0901, Birkbeck, Department of Economics, Mathematics \& Statistics.

Statskonsult (2007). Evaluering av HØYKOM [Evaluation of HØYKOM].

Stene, R. J. (2001). Seksualforbrytelser - skjebner i rettssystemet [sexual crimes fates in the judicial system]. Samfunnsspeilet, (3):2-12.

Stevenson, B. and Wolfers, J. (2007). Marriage and divorce: Changes and their driving forces. The Journal of Economic Perspectives, 21(2):27-52.

St.meld.nr. 38 (1997-1998). IT-kompetanse $i$ et regionalt perspektiv [A regional perspective on IT-competency]. Ministry of Trade and Industry.

St.meld.nr. 49 (2002-2003). Breiband for kunnskap og vekst [Broadband for knowledge and growth]. Ministry of Trade and Industry.

Ward, M. R. (2007). Teaching digital piracy. Working Papers 0701, University of Texas at Arlington, Department of Economics.

Yi, M. H. and Choi, C. (2005). The effect of the internet on inflation: Panel data evidence. Journal of Policy Modeling, 27(7):885-889.

Zillman, D. (1971). Excitation transfer in communication-mediated aggressive behavior. Journal of Experimental Social Psychology, 7:419-434.

Zillman, D. and Bryant, J. (1984). Effects of massive exposure to pornography. In Malamuth, N. and Donnerstein, E., editors, Pornography and sexual aggression. New York: Academic Press. 

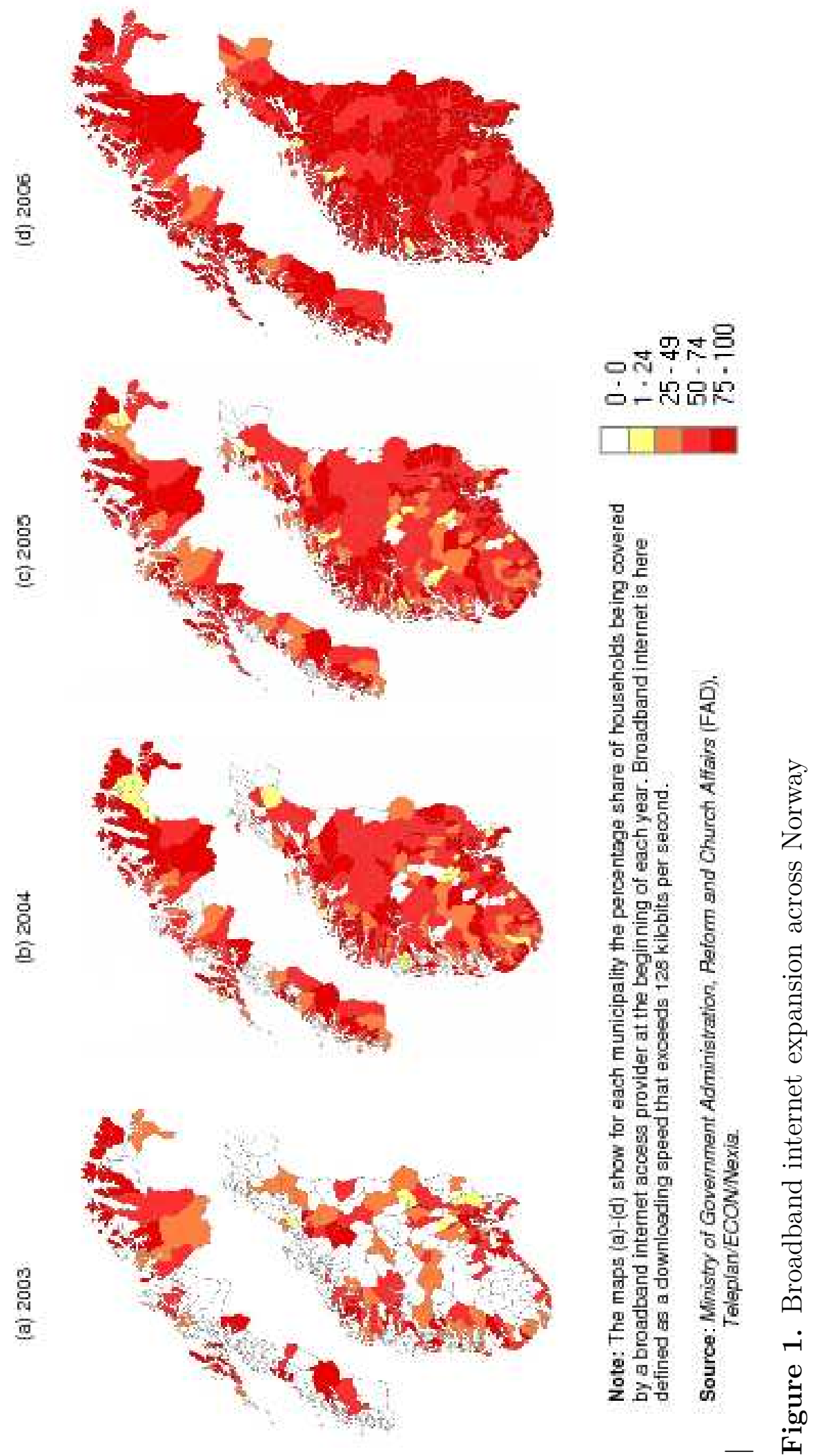


\section{Broadband Coverage Rates}

2000-2008

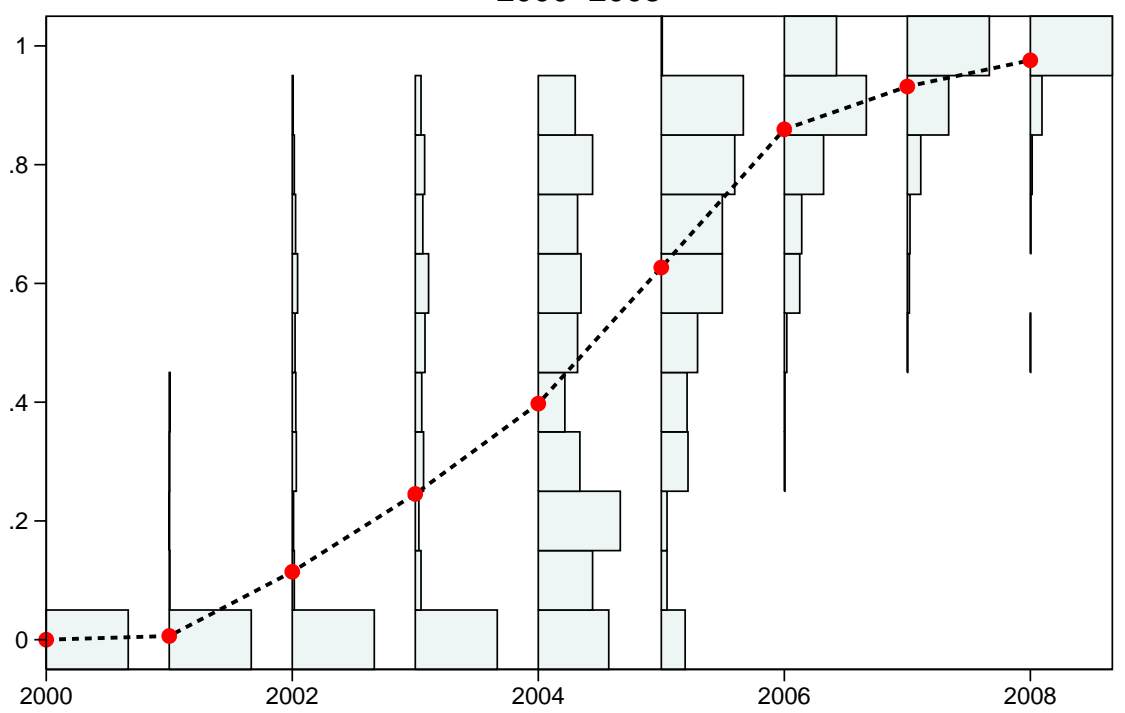

(a) Coverage rates

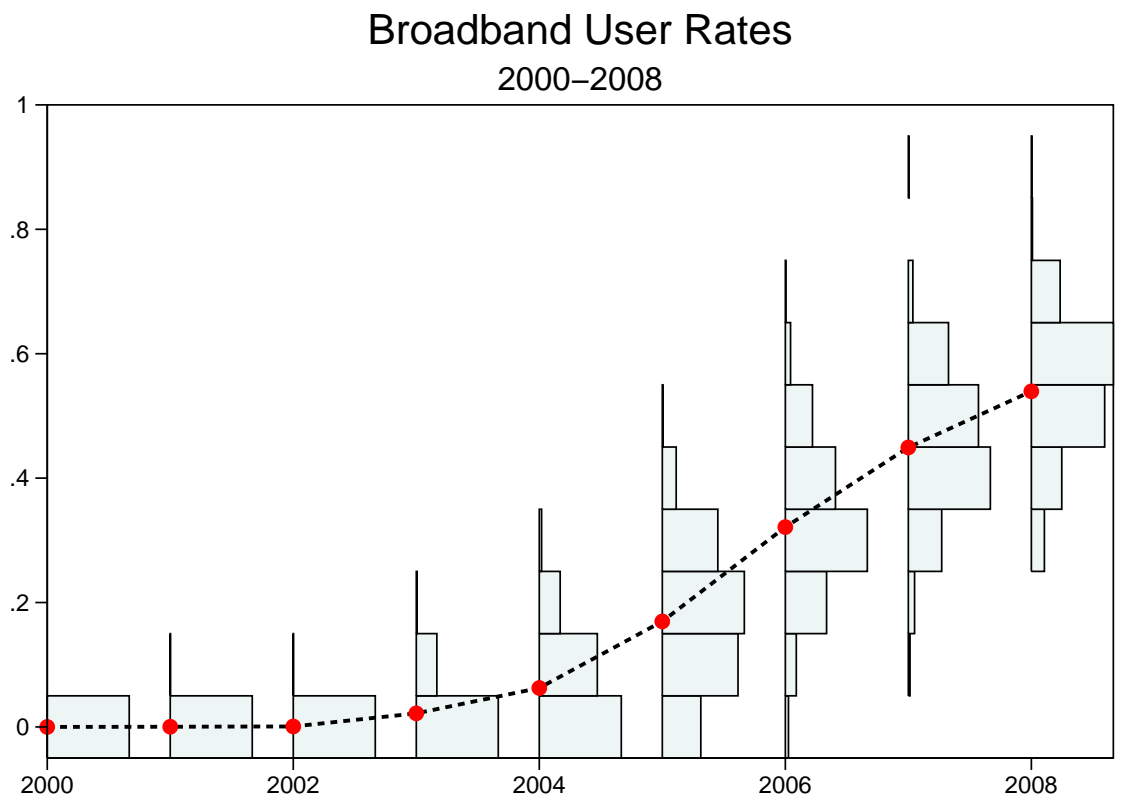

(b) User rates

Figure 2. Internet user and coverage rates, averages and distribution across municipalities, 2000-2008

Note: Figures show the overall mean and distribution of broadband user rates (panel a) and coverage rates (panel b) across municipalities for each year during the period 2000-2008. 

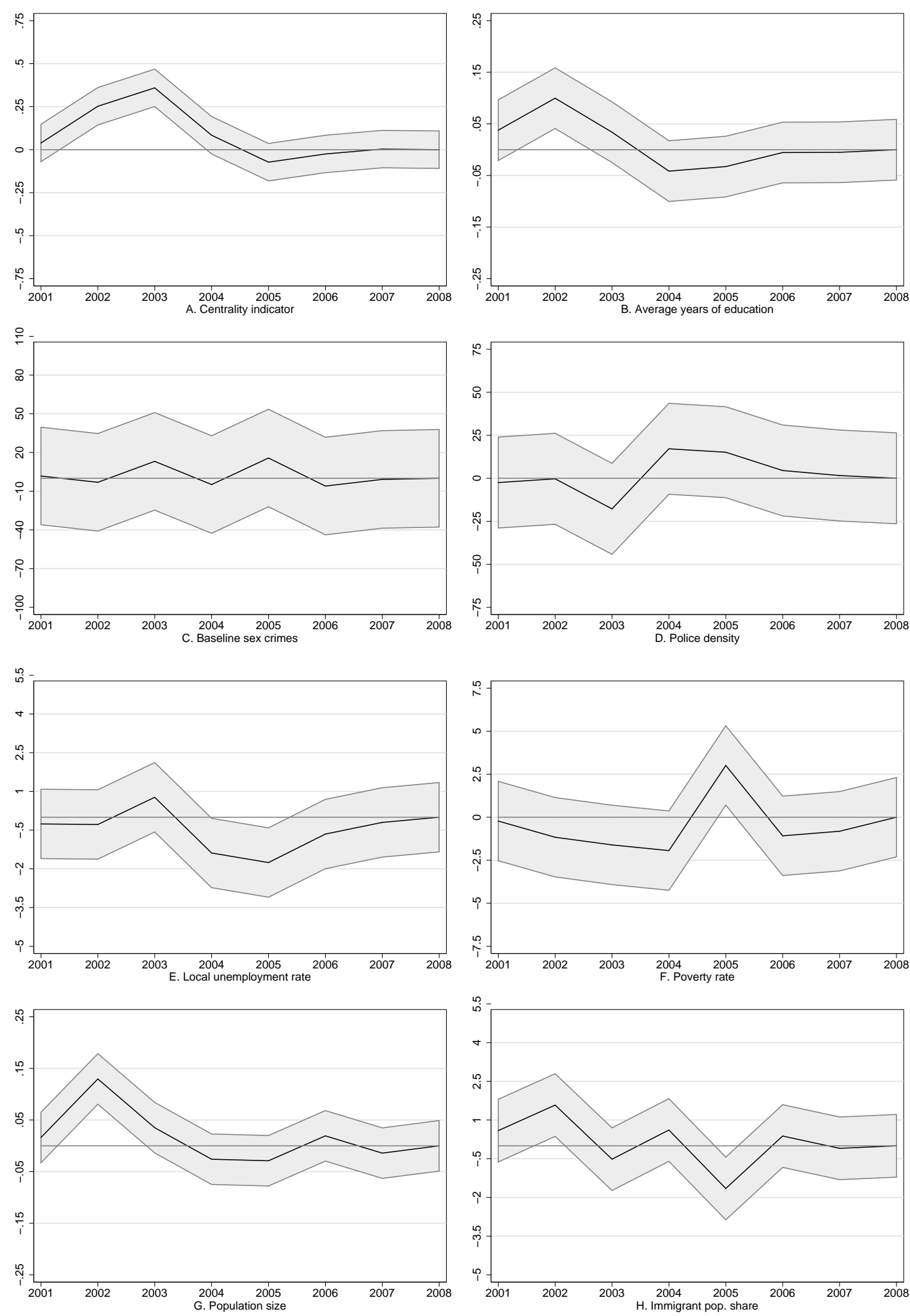

Figure 3. Broadband expansion regressed on baseline municipality characteristics, 2000-2008

Note: We regress changes in coverages rates on municipality specific baseline characteristics interacted with time dummies, controlling for municipality fixed effects. The figures plot interaction terms for each variable. 


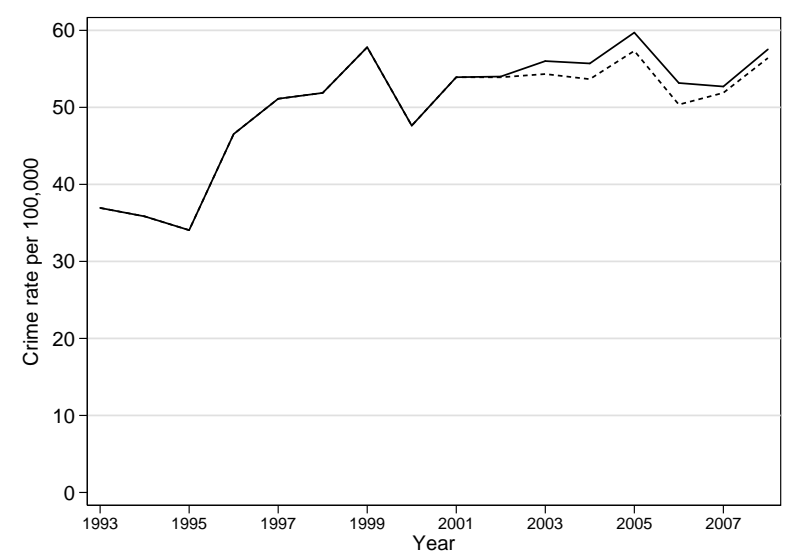

(a) All sex crimes

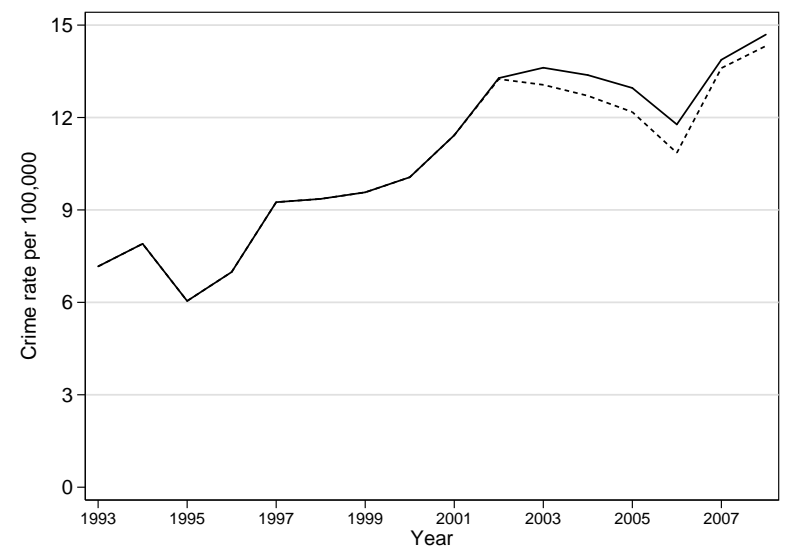

(b) Rapes

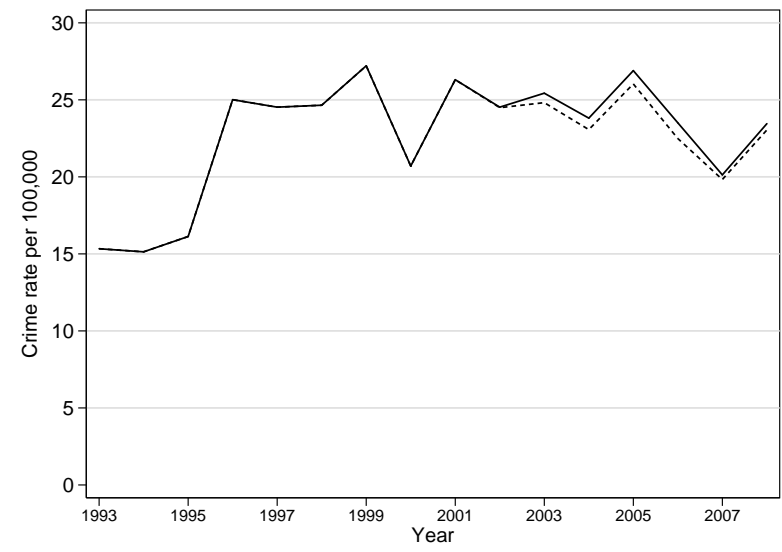

(c) Child sex abuse

Figure 4. Actual and predicted time trends

Note: Solid line $=$ actual crime rate. Dashed line $=$ counterfactual crime rate in the case of no broadband expansion. Shaded area $=95 \%$ confidence intervals for the counterfactual crime rate. The counterfactual crime rate is given by the actual crime rate minus the predicted effect of internet use on crime. In each year, the predicted effect of internet use on crime is calculated as the increase in the coverage rate in the previous year multiplied by the first stage times the LATE. 


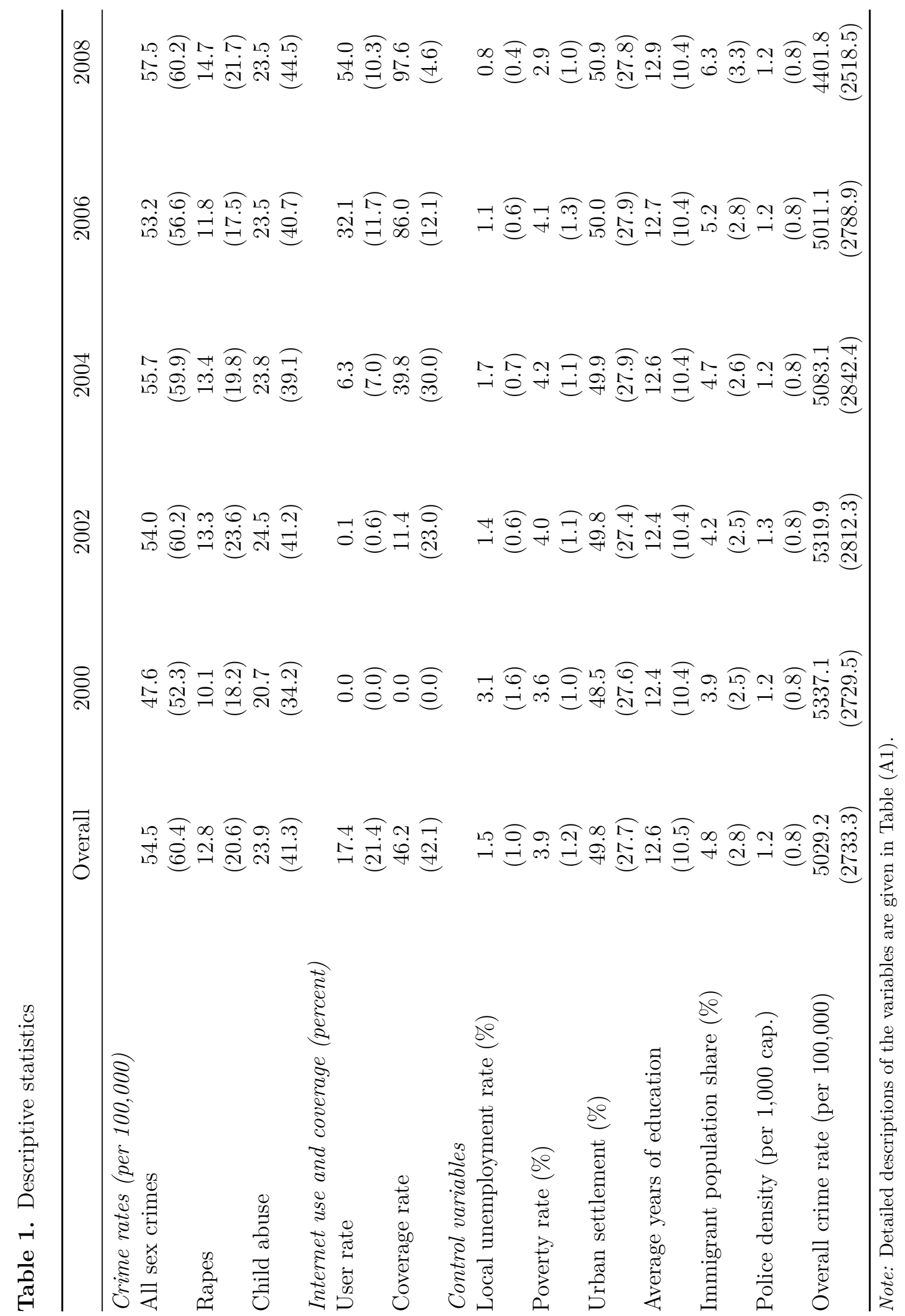




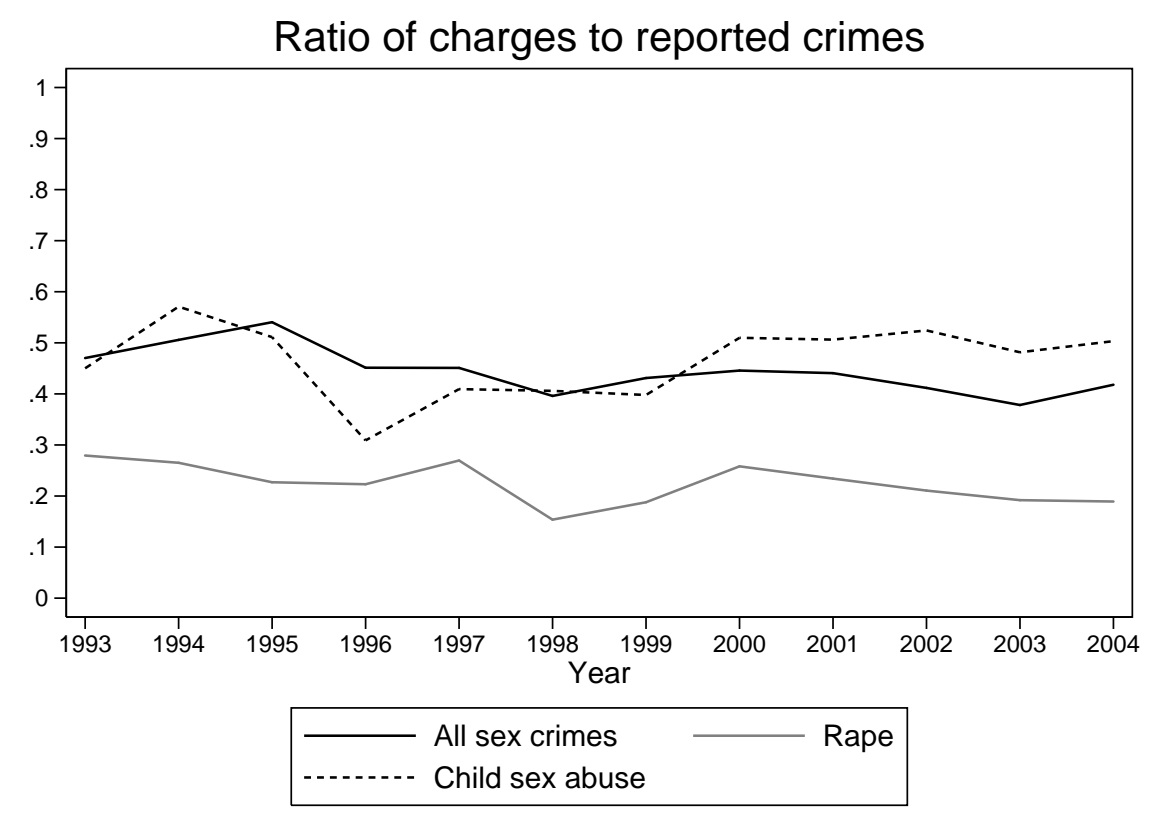

Figure 5. Ratio of charges to reported crimes, 1993-2004

Note: $\underline{\text { Charges/Crimes }}=$ \# reported crimes that led to a criminal charge / \# reported crimes.

Table 2. Fixed effect estimates of internet use on sex crime

\begin{tabular}{lcccc}
\hline All sex crimes & $0.466^{* *}$ & $0.549^{* * *}$ & $0.546^{* *}$ & $0.570^{* * *}$ \\
& $(0.197)$ & $(0.212)$ & $(0.212)$ & $(0.210)$ \\
Rape & $0.141^{* *}$ & $0.127^{*}$ & $0.127^{*}$ & $0.130^{*}$ \\
& $(0.071)$ & $(0.071)$ & $(0.071)$ & $(0.071)$ \\
& & & & \\
Child sex abuse & 0.158 & 0.180 & 0.180 & 0.193 \\
& $(0.134)$ & $(0.147)$ & $(0.147)$ & $(0.145)$ \\
$\begin{array}{l}\text { Demographic controls } \\
\text { Police density }\end{array}$ & & & $\checkmark$ \\
Other crimes & & $\checkmark$ & $\checkmark$ & $\checkmark$ \\
\hline
\end{tabular}

Note: Crime rates are calculated per 100,000 persons. Effects are reported per percentage point increase in the internet user rate. Standard errors are heteroskedasticity robust and clustered at the municipality level. Regressions are based on 422 municipalities $\times 8$ years $=3376$ observations. All regressions include municipality fixed effects and year dummies. Detailed descriptions of control variables are given in Table A1 $* \mathrm{p}<0.10,{ }^{* *}<0.05,{ }^{* * *} \mathrm{p}<0.01$. 


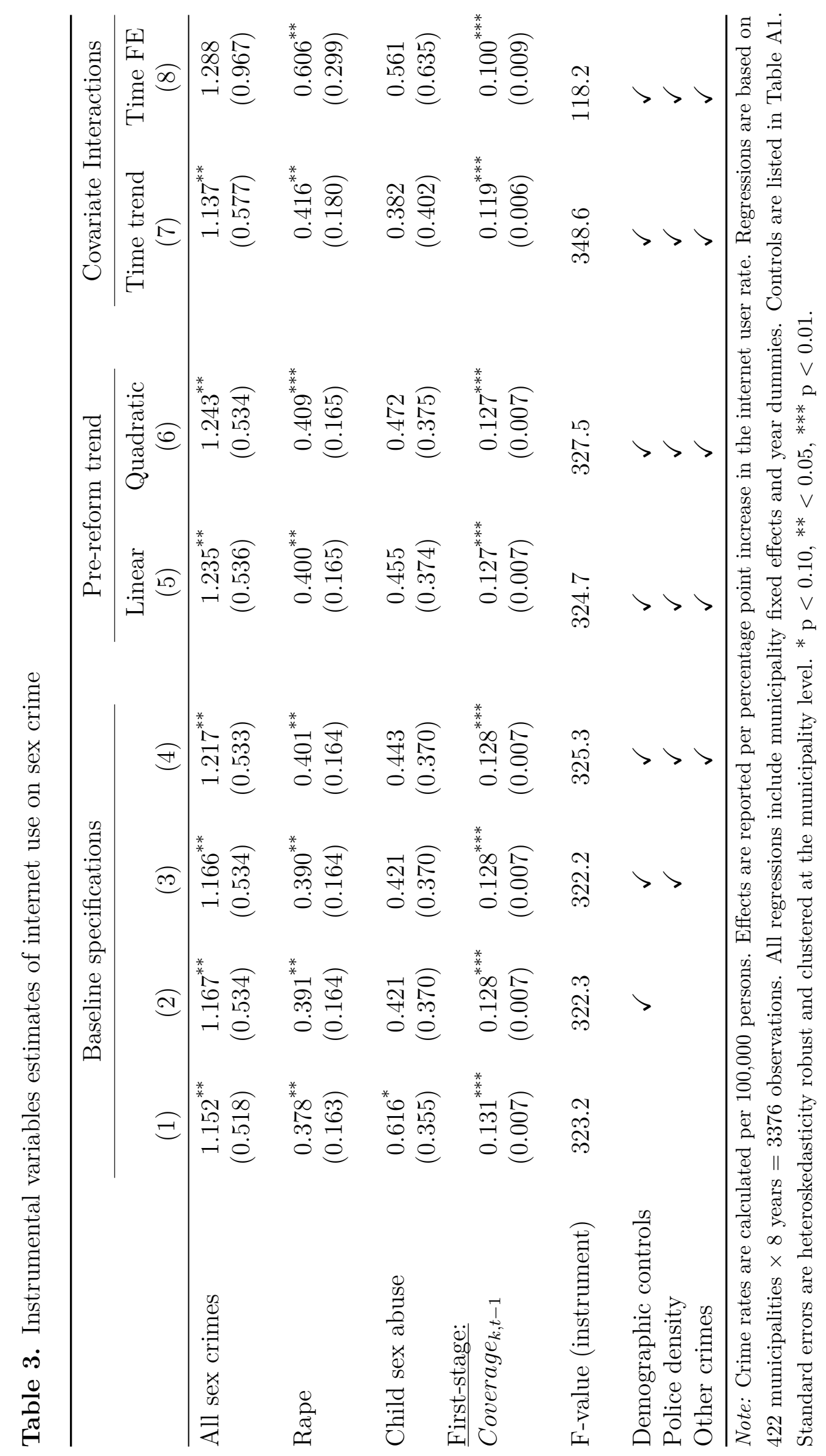




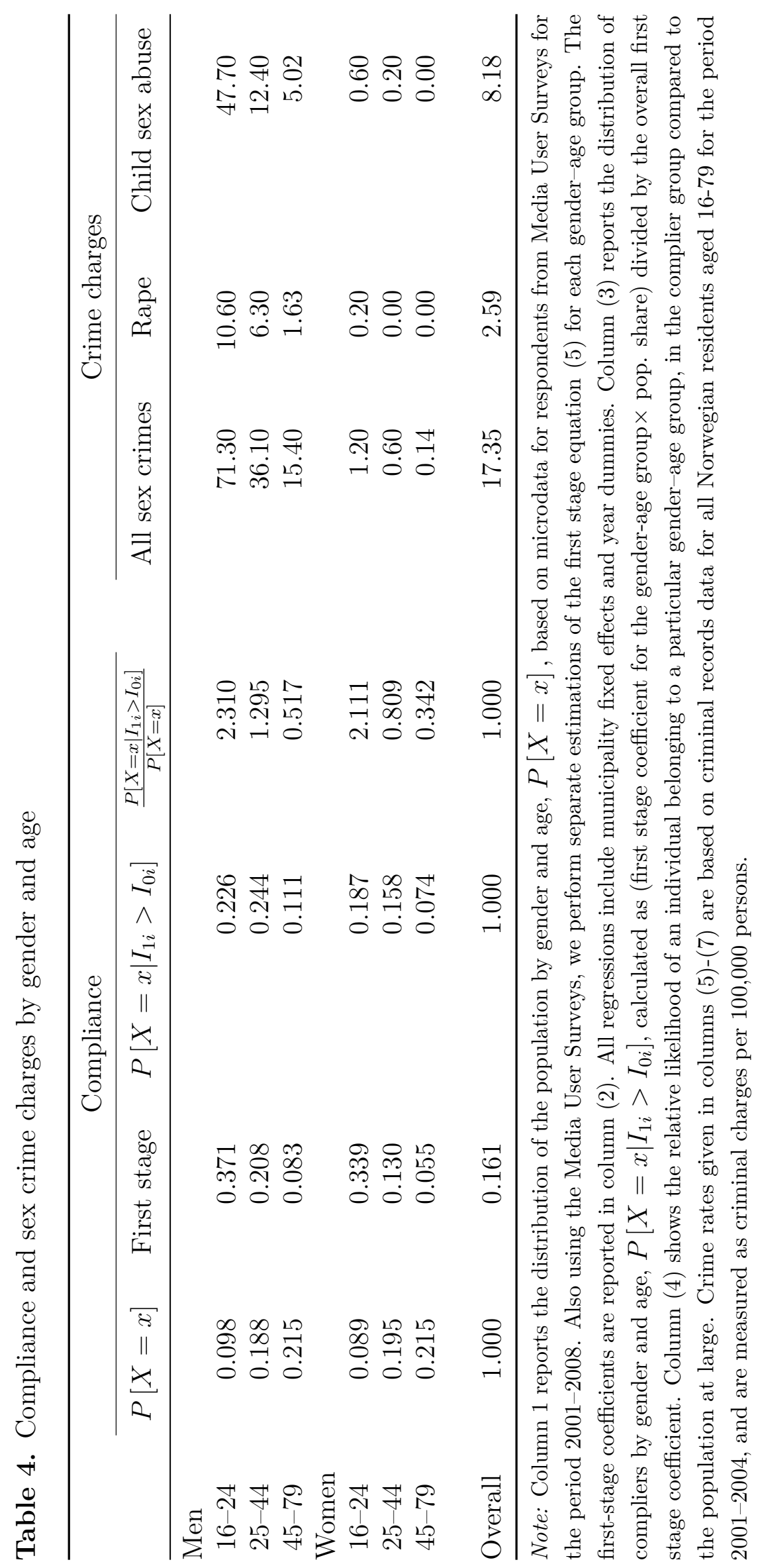


Table 5. Placebo tests

\begin{tabular}{lccc}
\hline Baseline & $\begin{array}{c}\text { Pre-reform } \\
\text { outcomes }\end{array}$ & $\begin{array}{c}\text { Next year } \\
\text { usage }\end{array}$ \\
\hline All sex crimes & $1.217^{* *}$ & -0.682 & -0.543 \\
& $(0.533)$ & $(0.582)$ & $(1.263)$ \\
Rapes & $0.401^{* *}$ & -0.112 & -0.158 \\
& $(0.164)$ & $(0.152)$ & $(0.532)$ \\
Child abuse & 0.443 & -0.556 & 0.621 \\
First-stage: & $(0.371)$ & $(0.473)$ & $(0.900)$ \\
Coverage $_{k, t-1}$ & $0.128^{* * *}$ & $0.133^{* * *}$ & \\
Coverage $_{k, t+1}$ & $(0.007)$ & $(0.007)$ & $0.054^{* * *}$ \\
& & & $(0.008)$ \\
\hline
\end{tabular}

Note: Crime rates are calculated per 100,000 persons. Effects are reported per percentage point increase in the internet user rate. Regressions are based on 422 municipalities $\times 8$ years $=3376$ observations. For the baseline estimations we use data on reported crimes over the period 2001-2008. In column (2) we display results from regressions where we use data on reported crimes and controls from the pre-broadband expansion period 1993-2000, while broadband user rates and coverage rates are stll from the period 2001-2008. In column (3) we display results from regressions where we instrument user rate in year $t+1$ by coverage rate in year $t$, while controlling for coverage rates at $\mathrm{t}-1$. All regressions include municipality fixed effects, year dummies and all controls listed in Table A1 Standard errors are heteroskedasticity robust and clustered at the municipality level. * $\mathrm{p}<0.10,{ }^{* *}<0.05,{ }^{* * *} \mathrm{p}<0.01$.

Table 6. Alternative outcomes

\begin{tabular}{lccc}
\hline & Overall crime & Vandalism & Theft \\
\hline Effect of internet use & -4.221 & -0.082 & -3.720 \\
& $(9.816)$ & $(1.336)$ & $(6.066)$ \\
Dependent mean & 4933.8 & 333.4 & 2192.4 \\
\hline
\end{tabular}

Note: Crime rates are calculated per 100,000 persons. Effects are reported per percentage point increase in the internet user rate. Standard errors are heteroskedasticity robust and clustered at the municipality level. Regressions are based on 422 municipalities $\times 8$ years $=3376$ observations. All regressions include municipality fixed effects, year dummies and all controls listed in Table A1 $* \mathrm{p}<0.10,{ }^{* *}<0.05,{ }^{* * *} \mathrm{p}<0.01$. 
Table 7. Effect of internet use on reporting

\begin{tabular}{lccccc}
\hline & \multicolumn{2}{c}{ Charges/Crimes } & & \multicolumn{2}{c}{ Time to report (days) } \\
\cline { 2 - 3 } & Dep. mean & Effect & & Dep. mean & Effect \\
\hline All sex crimes & 0.412 & -0.0008 & & 213.8 & -2.92 \\
& & $(0.0098)$ & & & $(3.13)$ \\
Rape & 0.206 & -0.0154 & & 80.9 & 0.96 \\
& & $(0.0133)$ & & \\
Child sex abuse & 0.503 & 0.0074 & & 240.6 & 5.26 \\
& & $(0.0135)$ & & $(4.04)$ \\
\hline
\end{tabular}

Note: Crime rates are calculated per 100,000 persons. Effects are reported per percentage point increase in the internet user rate. $\underline{\text { Charges/Crimes }}=$ \# reported crimes that led to a criminal charge / \# reported crimes. $\mathrm{N}=422$ municipalities $\times 4$ years $(2001-04)=1688$. Time to report $=$ days between the date when crime was reported to the police and the date when the crime was allegedly committed (annual average at the municipality level). $\mathrm{N}=422$ municipalities $\times 8$ years $(2001-08)=3376$. All regressions include municipality fixed effects, year dummies and all controls listed in Table A1 Standard errors are heteroskedasticity robust and clustered at the municipality level. ${ }^{*} \mathrm{p}<0.10,{ }^{* *}<0.05,{ }^{* * *} \mathrm{p}<0.01$.

Table 8. Border areas

\begin{tabular}{lcc}
\hline & Border areas & Non-border areas \\
\hline All sex crimes & 0.673 & $1.871^{* *}$ \\
& $(0.617)$ & $(0.956)$ \\
Rapes & 0.286 & $0.667^{* *}$ \\
& $(0.181)$ & $(0.306)$ \\
Child abuse & 0.172 & 0.547 \\
First-stage: & $(0.437)$ & $(0.560)$ \\
Coverage & & $0.116^{* * *}-1$ \\
& $0.139^{* * *}$ & $(0.012)$ \\
Municipalities & $(0.008)$ & 260 \\
\hline
\end{tabular}

Note: Crime rates are calculated per 100,000 persons. Effects are reported per percentage point increase in the internet user rate. Following Beatty et al. (2009), we define municipalities close to Sweden as border areas, whereas the remaining 260 municipalities are grouped as non-border areas. Standard errors are heteroskedasticity robust and clustered at the municipality level. All regressions include municipality fixed effects, year dummies and all controls listed in Table A1 * p $<0.10,{ }^{* *} \mathrm{p}<0.05,{ }^{* * *} \mathrm{p}<0.01$. 


\section{A Additional results}

Table A1. Variable definitions

\begin{tabular}{ll}
\hline Variable & Description \\
\hline Sex crimes & \\
All sex crimes & The number of reported alleged sexual abuses mentioned in the \\
& Norwegian Penal Code $\$ \$ 191-203$, including rape, attempted rape, \\
& sexual abuse of children, incest, procurement, prostitution, public \\
& exposé, and various other unapproved sexual abuses, committed in \\
& year t in a given municipality, divided by the population size of the \\
& municipality and multiplied by $100,000$. \\
& The number of reported rapes and attempted rapes as defined in \\
& the Norwegian Penal Code $\$ 192$ that were allegedly committed in \\
& year t in a given municipality, divided by the population size of the \\
& municipality and multiplied by $100,000$. \\
& The number of reported sexual abuse of children under 10,14 or 16 \\
& years of age as defined in the Norwegian Penal Code $\S 195-7$ and $\S$ \\
& 200 that were allegedly committed in year t in a given municipality, \\
& divided by the population size of the municipality and multiplied \\
& by $100,000$.
\end{tabular}

Internet

variables

User rate $\mathrm{t}$

Fraction of households residing in a given municipality who have a paid broadband internet subscription, with access speed at or above 256 kilobits per second at the beginning of year t.

Coverage rate $t$ Fraction of households residing in a given municipality who are being covered by a broadband internet provider, with access speed at or above 256 kilobits per second at the beginning of year t.

\section{Demographic}

controls

Age-group Percentage shares of the population residing in a given municipality belonging to the age-groups 16-21, 22-24, 25-34, 35-44, 45-54, 55-66, and 67 or above at the beginning of year $t$. 


\begin{tabular}{ll}
\hline Variable & Description \\
\hline Sex & Percentage shares of the female population residing in a given \\
& municipality belonging to the age-groups $16-21,22-24,25-34,35-44$, \\
& $45-54,55-66$, and 67 or above at the beginning of year t. \\
Immigrants & Percentage shares of the immigrant, male-immigrant, non-western \\
& immigrant, non-western male-immigrant, refugee and male-refugee \\
& populations residing in a given municipality belonging to the \\
& age-groups $16-21,22-24,25-34,35-44,45-54,55-66$, and 67 or above \\
Urban & at the beginning of year t. \\
settlement & Percentage share of the population in a given municipality residing \\
Education & in a densely populated locality at the beginning of year t. \\
& Average years of education among the age-group 16-59 residing in a \\
Income & given municipality at the beginning of year t. \\
& Average after-tax disposable income earned during year t by \\
Poverty & individuals aged 16-59 years residing in a given municipality. \\
& Percentage share of population having income below half of the \\
& median equivalent after-tax income in a given municipality, when \\
& the equivalent income is calculated using the OECD equivalence \\
& scale.
\end{tabular}

Unemployment Percentage share of the population aged 16-59 residing in a given municipality that is registered as fully unemployed at beginning of year t.

Police density Number of policemen in service in a given municipality at the beginning of year $t$, divided by the population size of the municipality and multiplied by 1,000 .

\section{Other crimes}

Overall crime rate

The total number of reported crimes (excluding sex crimes) allegedly committed in year $\mathrm{t}$ in a given municipality, divided by the population size of the municipality and multiplied by 100,000.

Theft The total number of thefts, including burglary (§ 147), larceny-theft (§ 257, §§ 261-262, § 258) and motor vehicle theft (§ 260) as defined in the Norwegian Penal Code $\S 147$ and $\S \S 257-262$ that were allegedly committed in year $\mathrm{t}$ in a given municipality, divided by the population size of the municipality and multiplied by 100,000 . 


\begin{tabular}{ll}
\hline Variable & Description \\
\hline Vandalism & The number of reported acts of vandalism as defined in the \\
& Norwegian Penal Code $\S \$ 291-294$ that were allegedly committed in \\
& year t in a given municipality, divided by the population size of the \\
& municipality and multiplied by $100,000$. \\
\hline
\end{tabular}

Table A2. Additional specification checks

\begin{tabular}{lccccc}
\hline & $\begin{array}{c}\text { Baseline } \\
(1)\end{array}$ & $\begin{array}{c}\text { No outliers } \\
(2)\end{array}$ & $\begin{array}{c}\text { No zeros } \\
(3)\end{array}$ & $\begin{array}{c}\text { No cities } \\
(4)\end{array}$ & $\begin{array}{c}\text { Incl. Spillovers } \\
(5)\end{array}$ \\
\hline All sex crimes & $1.217^{* *}$ & $1.112^{* *}$ & $1.299^{* *}$ & $1.261^{* *}$ & $1.922^{* * *}$ \\
& $(0.533)$ & $(0.462)$ & $(0.555)$ & $(0.549)$ & $(0.737)$ \\
& & & & & \\
& $0.401^{* *}$ & $0.316^{* *}$ & 0.359 & $0.432^{* *}$ & 0.303 \\
& $(0.164)$ & $(0.148)$ & $(0.248)$ & $(0.168)$ & $(0.224)$ \\
Rapes & 0.443 & 0.317 & 0.722 & 0.454 & $0.910^{*}$ \\
& $(0.370)$ & $(0.300)$ & $(0.516)$ & $(0.382)$ & $(0.519)$ \\
First-stage: $_{\text {Coverage }_{k, t-1}}$ & $0.128^{* * *}$ & $0.129^{* * *}$ & $0.103^{* * *}$ & $0.128^{* * *}$ & $0.127^{* * *}$ \\
& $(0.007)$ & $(0.007)$ & $(0.007)$ & $(0.007)$ & $(0.007)$ \\
Coverage $_{k, t-1}$ neighbor & & & & & 0.005 \\
& & & & & $(0.007)$ \\
\hline
\end{tabular}

Note: Crime rates are calculated per 100,000 persons. Effects are reported per percentage point increase in the internet user rate. The baseline results are based on 422 municipalities $\times 8$ years $=3376$ observations. In column (2), we check the robustness of our results to extreme values by dropping all the observations with a value of the dependent variable higher than its 99.5 th percentile. In column (3), we drop all observations with zero values of the dependent variable, whereas we drop the 5 largest cities in Norway, i.e. Oslo, Bergen, Trondheim, Stavanger and Kristiansand, in column (4). Outcome variable in column (5) includes crime in neighboring municipalities. All regressions include municipality fixed effects, year dummies and all controls listed in Table A1. Standard errors are heteroskedasticity robust and clustered at the municipality level. ${ }^{*} \mathrm{p}<0.10,{ }^{* *}$ $\mathrm{p}<0.05, * * * \mathrm{p}<0.01$. 
Table A3. Effect of broadband internet expansion on sorting

\begin{tabular}{lcccccc}
\hline & & \multicolumn{2}{c}{ Men } & & \multicolumn{2}{c}{ Women } \\
\cline { 3 - 4 } \cline { 6 - 7 } & All & $16-24$ & $25-44$ & & $16-24$ & $25-44$ \\
\hline Entry $_{k t}$ & 0.000 & 0.001 & -0.002 & & 0.004 & 0.000 \\
& $(0.001)$ & $(0.003)$ & $(0.002)$ & & $(0.003)$ & $(0.001)$ \\
Dependent mean & 0.051 & 0.083 & 0.055 & & 0.108 & 0.051 \\
Exit & & & & & & \\
& -0.001 & -0.002 & 0.001 & & -0.002 & -0.000 \\
Dependent mean & $0.001)$ & $(0.003)$ & $(0.001)$ & & $(0.004)$ & $(0.001)$ \\
\hline
\end{tabular}

Note: $\operatorname{Entry}_{k t}=\#$ individuals moving into municipalily $k$ in year $t /$ size municipality $k$ in year t. Exit $_{k t}=\#$ individuals moving out of municipality $k$ in year $t / \#$ similar individuals in municipality $k$ at the start of year $t$. Standard errors are heteroskedasticity robust and clustered at the municipality level. Regressions are based on 422 municipalities $\times 8$ years $=3376$ observations. All regressions include municipality fixed effects and year dummies. 